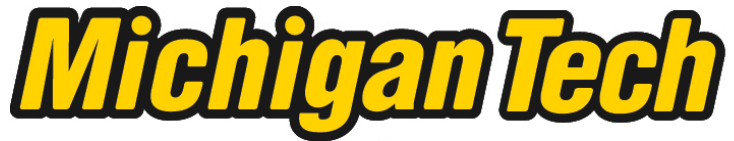 \\ Michigan Technological University Create the Future Digital Commons @ Michigan Tech
}

Dissertations, Master's Theses and Master's Reports - Open

Dissertations, Master's Theses and Master's

Reports

2012

\section{Design of a lab scale direct-filtration system and its application in process lab}

Shichang Ma

Michigan Technological University

Follow this and additional works at: https://digitalcommons.mtu.edu/etds

Part of the Civil and Environmental Engineering Commons

Copyright 2012 Shichang Ma

\section{Recommended Citation}

Ma, Shichang, "Design of a lab scale direct-filtration system and its application in process lab ", Master's report, Michigan Technological University, 2012.

https://doi.org/10.37099/mtu.dc.etds/504

Follow this and additional works at: https://digitalcommons.mtu.edu/etds

3 Part of the Civil and Environmental Engineering Commons 


\title{
Design of a Lab Scale Direct-Filtration System and Its Application in Process Lab
}

Shichang Ma

\author{
A REPORT
}

Submitted in partial fulfillment of the requirements for the degree of MASTER OF SCIENCE

Environmental Engineering

MICHIGAN TECHNOLOGICAL UNIVERSITY

2012 
This report, "Design of a Lab Scale Direct-Filtration System and Its Application in Process Lab", is hereby approved in partial fulfillment of the requirements for the Degree of MASTER OF SCIENCE IN Environmental Engineering.

Department of Civil and Environmental Engineering

Signatures:

Report Advisor

Dr. David Hand

Committee Member

Dr. Paul Doskey

Committee Member

Dr. Tony Rogers

Department Chair

Dr. David Hand

Date 


\section{Abstract}

The Environmental Process and Simulation Center (EPSC) at Michigan Technological University started accommodating laboratories for an Environmental Engineering senior level class CEE 4509 Environmental Process and Simulation Laboratory since 2004. Even though the five units that exist in EPSC provide the students opportunities to have hands-on experiences with a wide range of water/wastewater treatment technologies, a key module was still missing for the student to experience a full cycle of treatment. This project fabricated a direct-filtration pilot system in EPSC and generated a laboratory manual for education purpose. Engineering applications such as clean bed head loss calculation, backwash flowrate determination, multimedia density calculation and run length prediction are included in the laboratory manual. The system was tested for one semester and modifications have been made both to the direct filtration unit and the laboratory manual. Future work is also proposed to further refine the module. 


\section{Table of Contents}

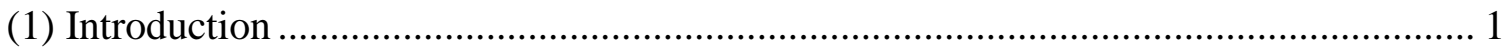

(2) Development of Direct-Filtration System in EPSC ................................................. 4

(2.1) Background about Direct Filtration................................................................... 4

Coagulation and Flocculation .................................................................................. 4

Direct Filtration Process Flow and Mechanism............................................................... 4

Calculations Relating to Direct Filtration ....................................................................... 6

(2.2) System Fabrication and Initial Lab Manual Development..................................... 11

(2.3) Laboratory Test, Problems and Modifications...................................................... 17

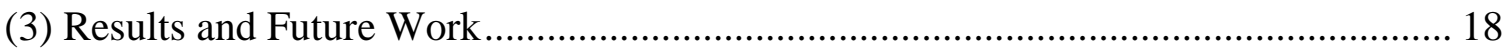

Acknowledgements .................................................................................................. 20

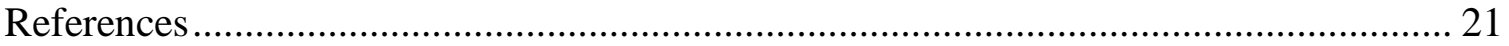

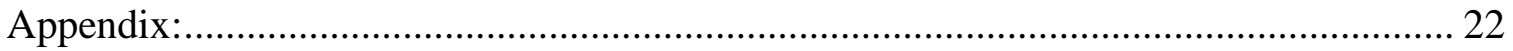




\section{List of Figures:}

Figure 1. Typical Process Train for Treatment of Surface Water by Direct Filtration....... 6

Figure 2. Effluent Turbidity Profile of Direct Filtration Process..................................... 7

Figure 3. Simplified Flow Chart of the Direct Filtration Unit .................................... 12

Figure 4. Overview of Direct Filtration Unit ............................................................. 12

Figure 5. Stainless Steel Tank for Influent Storage .................................................. 13

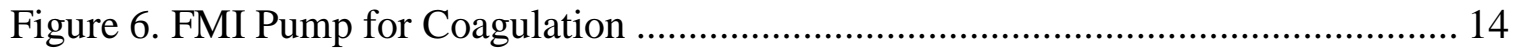

Figure 7. Packed Tank for Mixing .......................................................................... 14

Figure 8. Control Panel and Valve Setting for Filtration ............................................. 15

Figure 9. Control Panel and Valve Setting for Backwash ........................................ 15

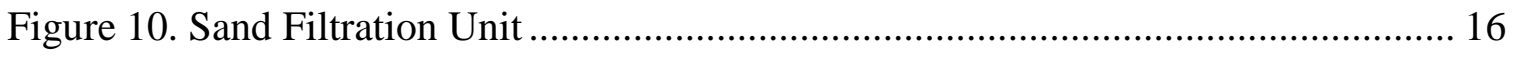

\section{List of Tables:}

Table 1. Summary of Modules that Exist in EPSC ............................................................... 2 


\section{(1) Introduction}

Most suspended matter is filtered from groundwater during natural filtration process when they pass through porous soil into aquifers. However, most surface water is subject to contamination from different natural, human and animal activities. The USEPA (U.S. Environmental Protection Agency) Surface Water Treatment Rule requires all surface water, and ground water resources under direct influence of surface water to be treated by continuous filtration and disinfection before drinking. Part of the water treatment technology, slow san filtration was first tried back in the 1900s to treat turbidity in drinking water; it was proven inefficient since organic matter easily clogs the system. Later on, industry started using chemical flocculation followed by sedimentation to resolve this issue. It was not until 1977 when USEPA's National Interim Primary Drinking Water Regulations lowered the acceptable turbidity from 5 NTU to 1 NTU that direct-filtration started showing its advantages over traditional filtration process. These advantages include: lower capital cost, better performance in removing particulates, and less space required as a result of the absence of sedimentation or flotation. The limitation of direct filtration is that high quality of source water is required. Later on engineers kept working on upgrading direct filtration technology. Direct filtration is now commonly used with a combination of pre-oxidation, powdered activated carbon (PAC) addition, and in some cases followed by granular activated carbon (GAC) adsorption depending upon the different treatment objectives. 
As for Environmental Engineering undergraduate education, the most difficult part is getting students with hands-on experiences in order to better understand unit processes in water and wastewater treatment. Environmental Process Simulation Center (EPSC), located in Dow106 at Michigan Tech, was designed to provide students with hands-on experience in working with water/wastewater and air pollution treatment processes. Environmental Process and Simulation Laboratory (EPSL) is a course offered to environmental engineering students in 2000 using the facilities in EPSC. Professors in the department have been working continuously on refining the course. By 2011, five major processes have been fabricated for EPSL and mature lab manuals have been developed for each process. Summarized information about these processes is listed in Table 1.

Table 1. Summary of Modules that Exist in EPSC

\begin{tabular}{|c|c|c|c|}
\hline $\begin{array}{l}\text { Module } \\
\text { Process }\end{array}$ & Technology Description & $\begin{array}{c}\text { EPA Best } \\
\text { Available } \\
\text { Technology } \\
\text { (BAT) }\end{array}$ & Unit Usage \\
\hline $\begin{array}{c}\text { Air } \\
\text { Stripping }\end{array}$ & $\begin{array}{l}\text { Technology in which } \\
\text { contaminates are } \\
\text { transferred from water to } \\
\text { air. }\end{array}$ & Yes & $\begin{array}{c}\text { Water contaminated by } \\
\text { volatile organic } \\
\text { compounds (VOCs) }\end{array}$ \\
\hline $\begin{array}{c}\text { Ion } \\
\text { Exchange }\end{array}$ & $\begin{array}{c}\text { The process of removing } \\
\text { undesirable ions in subject } \\
\text { water by running it through } \\
\text { a bed of ion exchange } \\
\text { material }\end{array}$ & Yes & $\begin{array}{c}\text { Water contaminated by } \\
\text { heavy metal }\end{array}$ \\
\hline Jar Testing & $\begin{array}{l}\text { A series of process where } \\
\text { coagulation, flocculation } \\
\text { and sedimentation happen } \\
\text { all in a set of lab scale jars }\end{array}$ & No & $\begin{array}{c}\text { A process simulating } \\
\text { coagulation and } \\
\text { flocculation processes in a } \\
\text { water treatment plant for } \\
\text { obtaining design } \\
\text { parameters }\end{array}$ \\
\hline
\end{tabular}




\begin{tabular}{|c|c|c|c|}
\hline $\begin{array}{c}\text { Granular } \\
\text { Activated } \\
\text { Carbon } \\
\begin{array}{c}\text { Adsorption } \\
\text { Process }\end{array}\end{array}$ & $\begin{array}{c}\text { Removal of organic } \\
\text { contaminants using } \\
\text { physical adsorption in a } \\
\text { fixed-bed process }\end{array}$ & No & $\begin{array}{c}\text { Used for obtaining design } \\
\text { parameters for a GAC } \\
\text { adsorption plant }\end{array}$ \\
\hline SBR & $\begin{array}{c}\text { An activated sludge process } \\
\text { where waste water get } \\
\text { treated in a single reactor } \\
\text { under continuous batch } \\
\text { treatment mode }\end{array}$ & Yes & $\begin{array}{c}\text { Used mainly for treating } \\
\text { wastewater with high } \\
\text { contents of nutrient }\end{array}$ \\
& & \\
\hline
\end{tabular}

Turbidity treatment for surface water is required in most treatment processes. One of the most commonly used systems for turbidity treatment is direct-filtration. In this project, a pilot scale direct filtration module is designed to enhance the students' EPSC experience; it will also further provide an opportunity for students to understand the application of coagulation and flocculation which they learned from jar testing. The direct filtration module consists of coagulation, flocculation and filtration. Future work is also proposed for further refinement of the direct filtration laboratory. 


\section{(2) Development of Direct-Filtration System in EPSC}

\section{(2.1) Background about Direct Filtration}

\section{Coagulation and Flocculation}

Negative charges on particles in most natural water create repulsive forces between particles and prevent them from attaching to each other or settling. Coagulation is a process of destabilizing suspended particles by adding coagulants, which empart positively charged ions in water to neutralize the negative charge on the surface of the particles. Following coagulation, flocculation increases the probability of contacts between suspended matters by introducing hydraulic gradients. Particles then flocculate and grow large enough to settle out by gravity. Coagulation and flocculation are used when the water body has a high turbidity, which has aesthetic effects of drinking water.

\section{Flow Filtration Mechanism and Direct Filtration Process}

There are basically four filtration mechanisms, Sedimentation, Interception, Inertia and Brownian Diffusion:

Sedimentation: the mechanism of sedimentation refers to the filtration when the gravity force and the associated settling velocity of the particle cause it to reach to the collector. 
Interception: when following the streamline, if a large enough particle lies close enough to the filter media surface, and hit on the media grain, it will get captured. This mechanism is called interception.

Inertia: inertia refers to the situation when larger particles move fast enough to travel off their original streamlines and hit on media grains.

Brownian Diffusion: very small particles like viruses travel randomly within the fluid due to thermal gradients. When there's diffusion for the particle towards median grains, it is called Brownian diffusion. Note this is only important to small particles with diameters less than 1 micron.

Rapid filtration is a water treatment technology that removes suspended matters in water by running water through a filter media. Besides straining, particles are removed when they adhere to the filter grains or deposited particles. When the water is pretreated with coagulant addition and flocculation before filtration, the process is called direct filtration. Direct filtration is normally suitable for treating water with a turbidity of less than 15 NTU. Advantages of direct filtration include reduced capital and O\&M cost, and high final water quality with turbidity lower than 0.1 NTU. Direct filtration normally consists of five major processes: inflow, coagulant introduction, flocculation, filtration and outflow. Water flows into the system, enters a rapid mixing system after the introduction of coagulant where flocculation occurs. The flocs then get removed as suspended particles flow through a dual or monomedia granular filter. A typical process train for treatment of surface water by direct filtration is shown below. (MWH, Water Treatment, Figure 4-5, 206). 


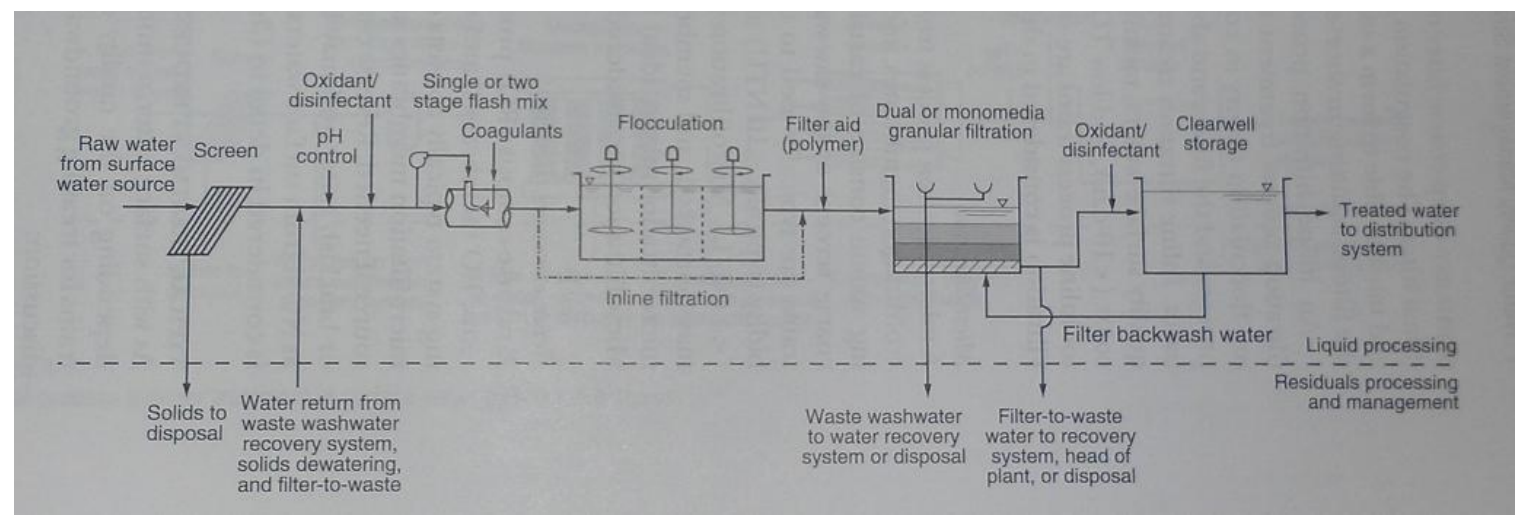

Figure 1. Typical Process Train for Treatment of Surface Water by Direct Filtration

\section{Calculations Relating to Direct Filtration}

The direct filtration process follows a four-stage cycle: filter ripening, effective filtration, breakthrough, and backwashing (see Figure 2 for turbidity profile). Ripening is a phase of media conditioning in which as the particulates buildup on the clean media the media becomes more efficient at collection. It allows some particles to pass through the filter media and creates up to two turbidity spikes. During the effective filtration stage, the filter is functioning within an acceptable effluent turbidity level. As the filter continues to collect particles, turbidity and head loss will both increase, resulting in the effluent exceeding the NTU limit or the head loss reaching the system limit head. Both of these results indicate breakthrough. Once breakthrough occurs, a backwashing cycle is necessary. Backwashing is the process of forcing clean water (also known as "wash" water) through the filter in the reverse direction to stir up the filter media and remove the various particles. Since backwashing requires the system to be taken offline, efficient backwashing is a critical step in direct-filtration. Ripening immediately follows 
backwashing and that completes a whole cycle. Calculation involving each part will be discussed below.

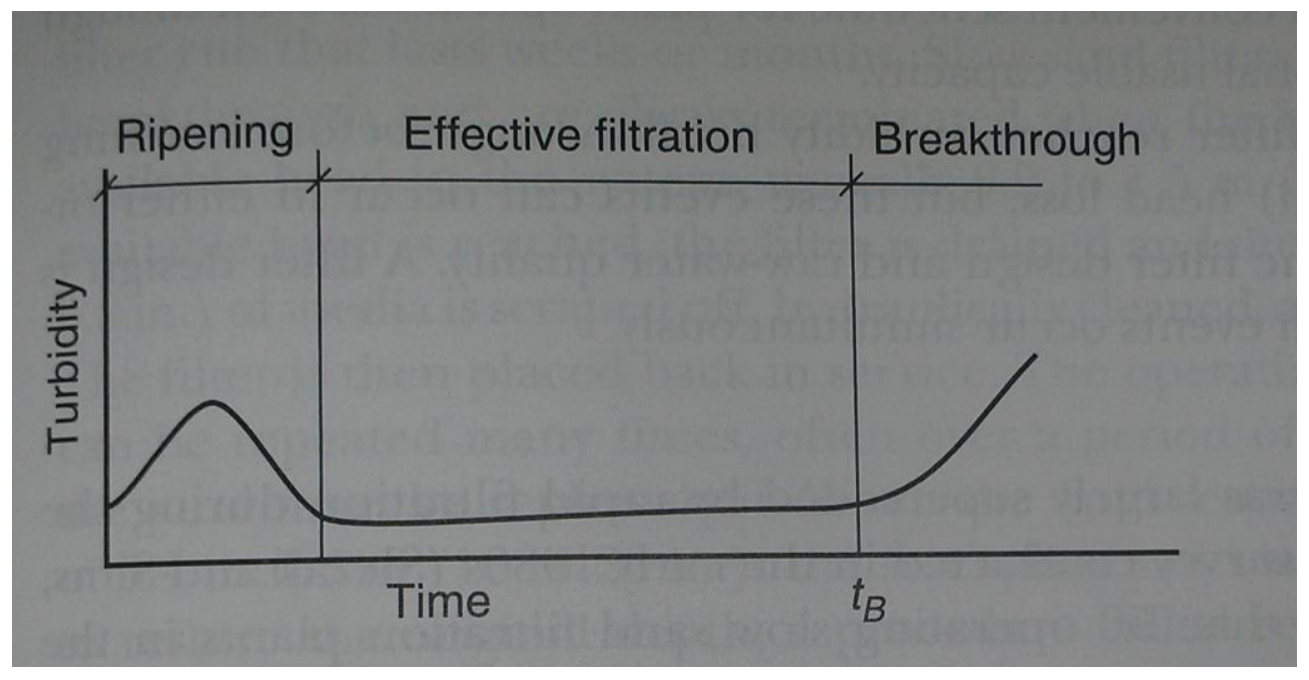

Figure 2. Effluent Turbidity Profile of Direct Filtration Process

\section{Filter Media}

During ripening and effective filtration stage, the properties of the filter media can greatly affect the time to breakthrough or time to limit head. These properties include: effective size, uniformity coefficient and granular bed porosity.

Effective Size (ES): "the media grain diameter at which 10 percent of the media by weight is smaller, as determined by a sieve analysis." (MWH, Water Treatment. 2012)

$$
E S=d_{10}
$$

Where ES = effective size

$$
\mathrm{d}_{10}=10^{\text {th }} \text { percentile media grain diameter, } \mathrm{mm}
$$


Uniformity Coefficient (UC): a coefficient that describes the uniformity of the granular media. When the filter media are of the same size, UC=1. Practically, $\mathrm{UC}>1$ and the smaller the UC is, the better the uniformity of the granular media.

$$
U C=\frac{d_{60}}{d_{10}}
$$

Where $d_{60}=60^{\text {th }}$ percentile media grain diameter, $\mathrm{mm}$

Granular Bed Porosity (ع): the ratio of void bed space over the total bed volume. The bed porosity has a great impact on head loss and filtration effectiveness.

$$
\varepsilon=\frac{V_{t}-V_{m}}{V_{t}}=\frac{V_{v}}{V_{t}}
$$

Where $\varepsilon=$ porosity, dimensionless

$\mathrm{V}_{\mathrm{t}}=$ total volume in media bed, $\mathrm{m}^{3}$

$\mathrm{V}_{\mathrm{v}}=$ void volume in media bed, $\mathrm{m}^{3}$

$\mathrm{V}_{\mathrm{m}}=$ volume of media, $\mathrm{m}^{3}$

\section{Hydraulics of Flow}

Reynolds Number (Re): the ratio of inertial movement over viscous movement.

$$
\operatorname{Re}=\frac{\rho_{\mathrm{w}} \mathrm{vL}}{\mu_{\mathrm{f}}}
$$

Where $\rho_{\mathrm{w}}=$ fluid density, $\mathrm{kg} / \mathrm{m}^{3}$

$\mathrm{v}=$ filtration rate (superfacial velocity), $\mathrm{m} / \mathrm{s}$

$\mu=$ dynamic viscosity of fluid, $\mathrm{kg} / \mathrm{ms}$ 


$$
\mathrm{d}=\text { media grain, } \mathrm{m}
$$

Clean Bed Head-loss: the theoretical head-loss of the clean bed can be calculated using the equation below:

$$
H_{L}=\kappa_{V} \frac{(1-\varepsilon)^{2}}{\varepsilon^{3}} \frac{\mu L v}{\rho_{W} g^{2}}+\kappa_{I} \frac{1-\varepsilon}{\varepsilon^{3}} \frac{L v^{2}}{g d}
$$

Where $\mathrm{H}_{\mathrm{L}}=$ Clean head loss across media bed, $\mathrm{m}$

$$
\begin{aligned}
& \kappa_{\mathrm{v}}=\text { head loss coefficient due to viscous forces, unitless } \\
& \kappa_{\mathrm{I}}=\text { head loss coefficient due to inertial forces, unitless }
\end{aligned}
$$

Porosity of Expanded Bed: during backwashing, a lot of times the bed needs to be expanded to clean the exhausted bed better. When the bed expands, the porosity changes, and the expanded porosity of the bed can be calculated using the equation below:

$$
\frac{L_{E}}{L_{F}}=\frac{1-\varepsilon_{F}}{1-\varepsilon_{E}}
$$

Where $L_{E}=$ depth of expanded bed, $m$

$$
\begin{aligned}
& \mathrm{L}_{\mathrm{F}}=\text { depth of fixed bed, } \mathrm{m} \\
& \varepsilon_{\mathrm{F}}=\text { porosity of expanded bed, dimensionless } \\
& \varepsilon_{\mathrm{F}}=\text { porosity of fixed bed, dimensionless }
\end{aligned}
$$

Backwash Flowrate: the backwash flowrate needs to reach a certain percent of expansion can be calculated using the equation below: 


$$
\begin{gathered}
v=\frac{\mu R e}{\rho_{W} d}=\frac{\mu}{\rho_{W} d}\left(\frac{-\kappa_{V}(1-\varepsilon)}{2 \kappa_{I}}+\frac{1}{2 \kappa_{I}} \sqrt{\kappa_{V}^{2}(1-\varepsilon)^{2}+4 \kappa_{I} \beta}\right) \\
\beta=\frac{g \rho_{W}\left(\rho_{P}-\rho_{W}\right) d^{3} \varepsilon^{3}}{\mu^{2}}
\end{gathered}
$$

Where $\beta=$ backwash calculation factor, dimensionless

Multimedia filters: when there's more than one layer of filters, in order to make sure that all media fluidize at the same backwash rate, the densities of these media need to follow the equation below:

$$
\frac{d_{1}}{d_{2}}=\left(\frac{\rho_{2}-\rho_{W}}{\rho_{1}-\rho_{W}}\right)^{0.625}
$$

Where $\mathrm{d}_{1}=$ grain diameter of media $1, \mathrm{~m}$

$$
\begin{aligned}
& \mathrm{d}_{2}=\text { grain diameter of media } 2, \mathrm{~m} \\
& \rho_{1}=\text { density of medium } 1, \mathrm{~kg} / \mathrm{m}^{3} \\
& \rho_{2}=\text { density of medium } 2, \mathrm{~kg} / \mathrm{m}^{3}
\end{aligned}
$$

Failure to choose the right media may cause one media to be washed out while fluidizing the other one.

Determination of Run Length: A simplified steady-state phenomenological model has been developed to predict the run length of effective filtration. Breakthrough occurs either when the effluent reaches the turbidity limit, or the head loss reaches the limit head. They can be calculated using the equation below:

$$
\begin{gathered}
t_{B}=\frac{\sigma_{B} L}{v_{F}\left(C_{o}-C_{E}\right)} \\
t_{H L}=\frac{\left(H_{T}-h_{L, O}\right) L}{k_{H L} v_{F}\left(C_{O}-C_{E}\right)}
\end{gathered}
$$




$$
\text { Where } \begin{aligned}
t_{B} & =\text { time to breakthrough, } \mathrm{h} \\
\sigma_{\mathrm{B}} & =\text { Specific deposit at breakthrough, } \mathrm{mg} / \mathrm{L} \\
\mathrm{L} & =\text { filter bed depth, } \mathrm{m} \\
\mathrm{C}_{\mathrm{o}} & =\text { influent concentration, } \mathrm{mg} / \mathrm{L} \\
\mathrm{C}_{\mathrm{e}} & =\text { effluent concentration, } \mathrm{mg} / \mathrm{L}
\end{aligned}
$$

In the equations above, $\sigma_{\mathrm{B}}$ and $\mathrm{k}_{\mathrm{HL}}$ can be obtained through pilot study. When several direct filtration runs are conducted with different media sizes, filtration rates and depths, $\mathrm{C}_{\mathrm{o}}, \mathrm{C}_{\mathrm{E}}, \mathrm{t}_{\mathrm{B}}, \mathrm{h}_{\mathrm{L}, \mathrm{O}}$, and $\mathrm{h}_{\mathrm{L}}$ are recorded at time $\mathrm{t}_{\mathrm{B}}$, and $\sigma_{\mathrm{B}}$ and $\mathrm{k}_{\mathrm{HL}}$ can be calculated using these two equations. A multivariate regression analysis can help determine the relationship between $\sigma_{\mathrm{B}}, \mathrm{k}_{\mathrm{HL}}$ and $\mathrm{h}, \mathrm{v}, \mathrm{ES}$. Use the result of the regression to calculate $\sigma_{\mathrm{B}}$ and $\mathrm{k}_{\mathrm{HL}}$ for the real world filtration plant and predict the run length with the given filter media.

\section{(2.2) System Fabrication and Initial Lab Manual Development}

The lab set-up can be described by the flow chart below. 


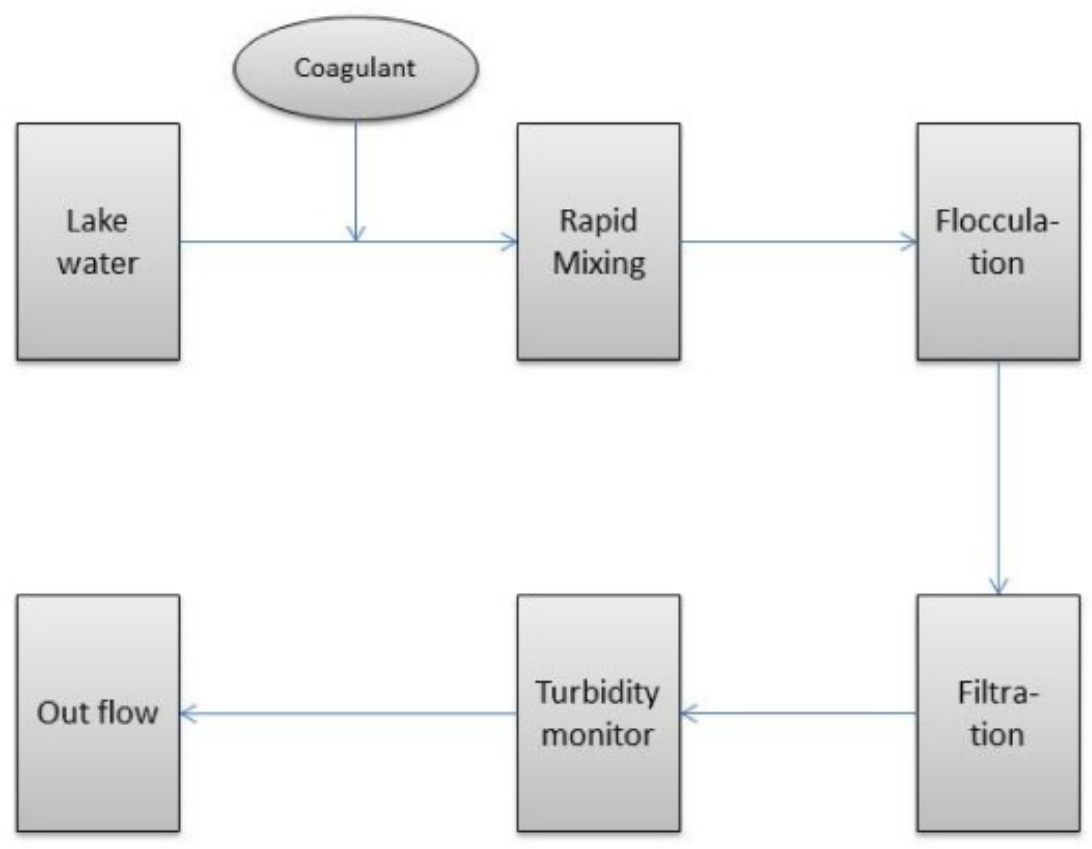

Figure 3. Simplified Flow Chart of the Direct Filtration Unit

An overview of the unit is shown below (see Figure 4). Detailed information is also discussed.

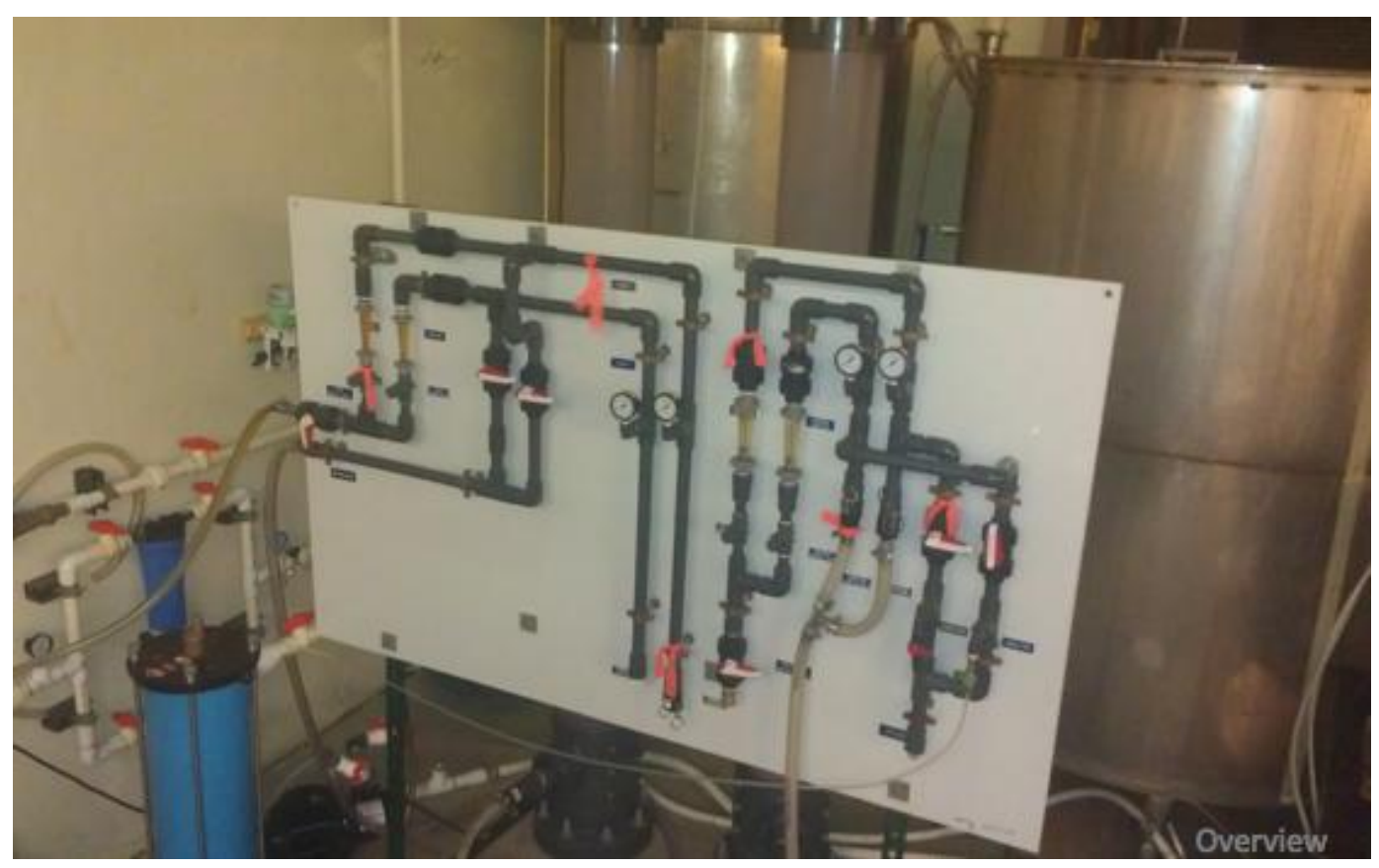

Figure 4. Overview of Direct Filtration Unit 
The lake water will be spiked and totally mixed in a stainless steel tank with bentonite to serve as our inflow, as is shown in the picture below (See Figure 5). Mixing is fulfilled by circulating the water from bottom to top of the tank:

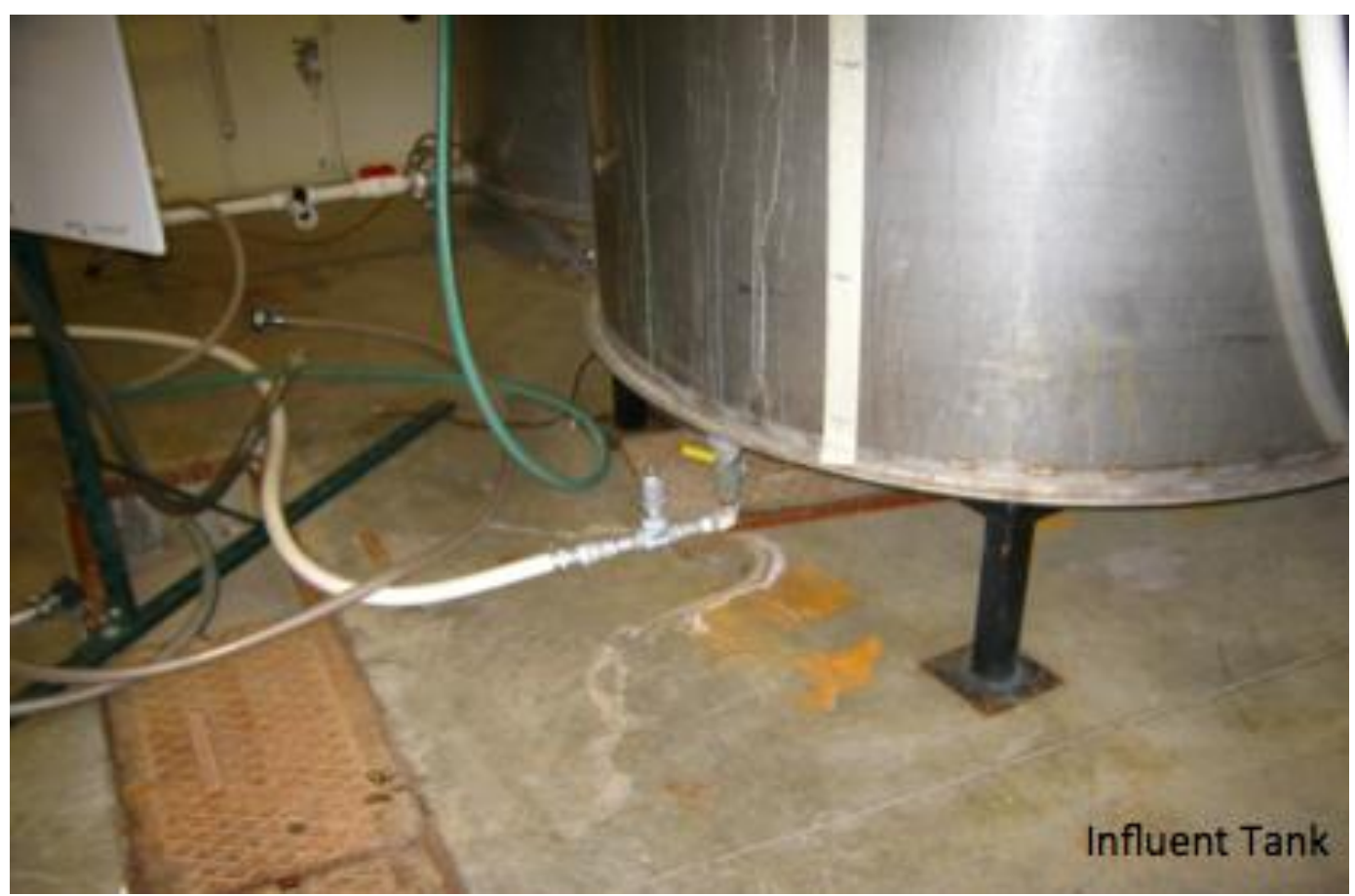

Figure 5. Stainless Steel Tank for Influent Storage

After mixing with bentonite, the coagulant will be introduced to the system with a FMI pump at desired flowrate and get mixed through a packing tank, as is shown below (see Figure 6, 7). 


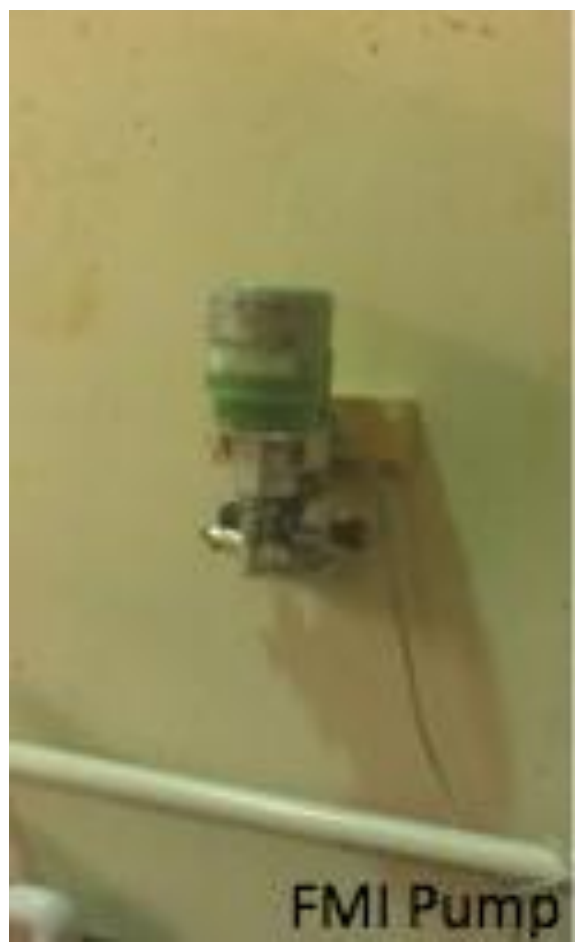

Figure 6. FMI Pump for Coagulation

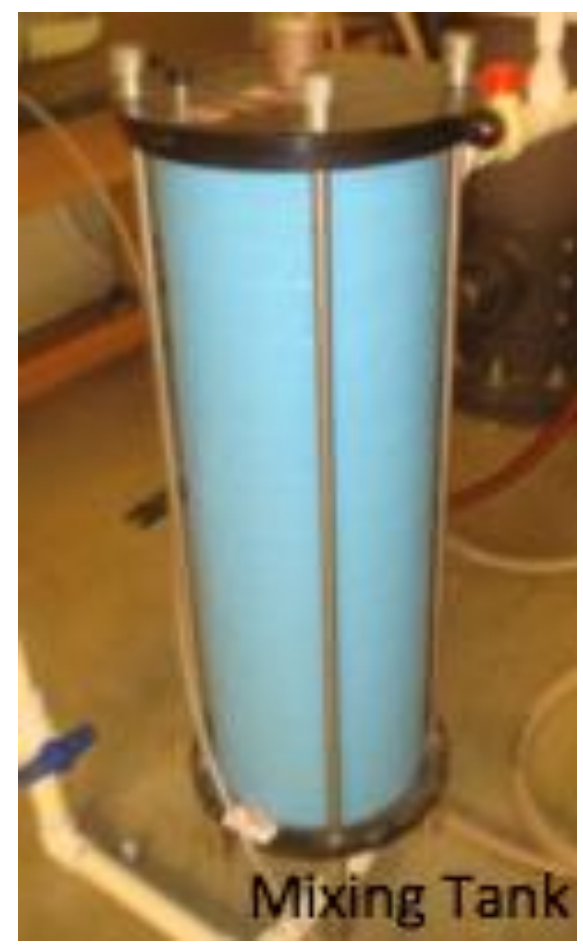

Figure 7. Packed Tank for Mixing

The control panel navigates the water to the right system, and through adjusting valves, back washing and direct filtration can be achieved. The flow of water and set up of valves for each process are shown in the pictures below (see Figure 8): 


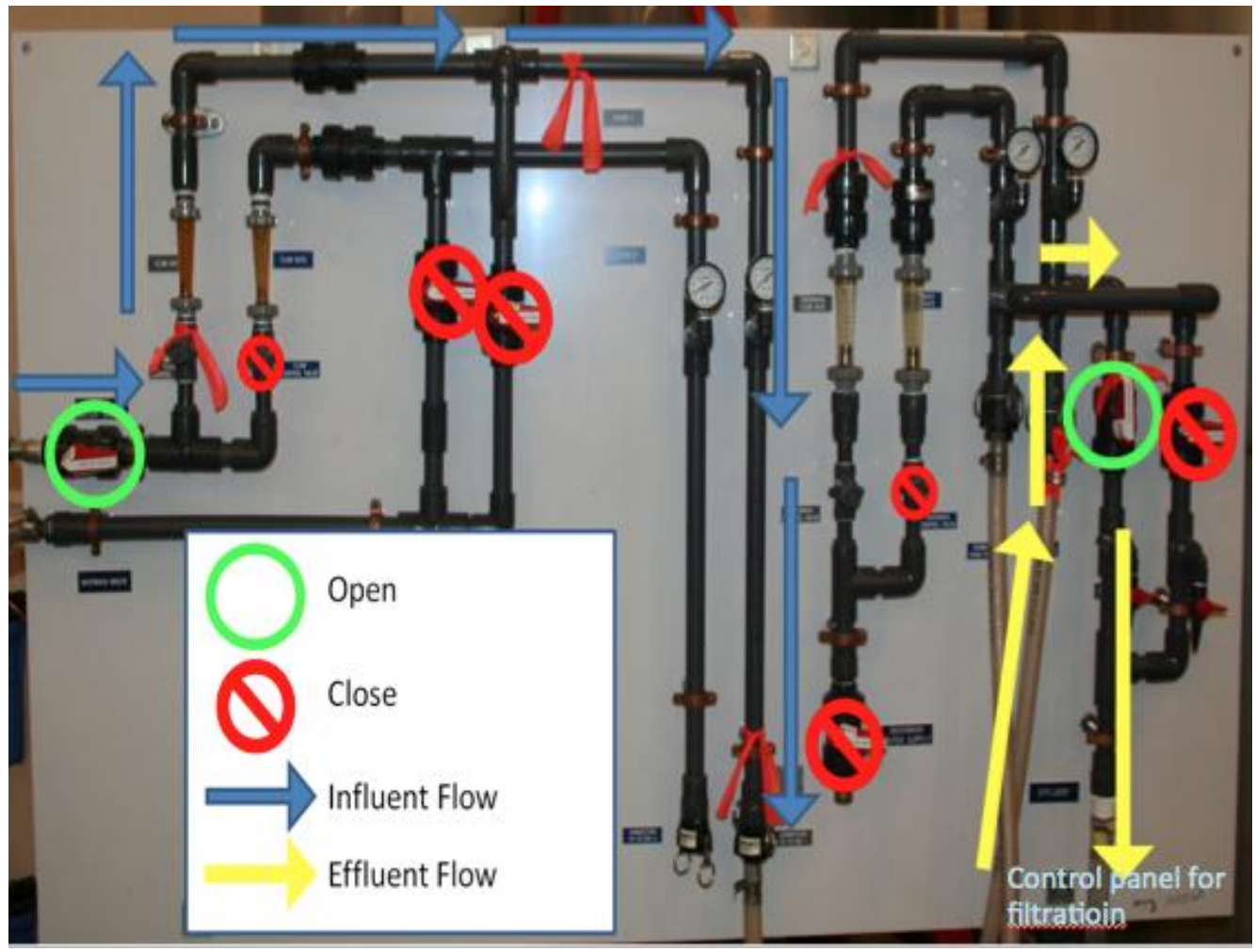

Figure 8. Control Panel and Valve Setting for Filtration

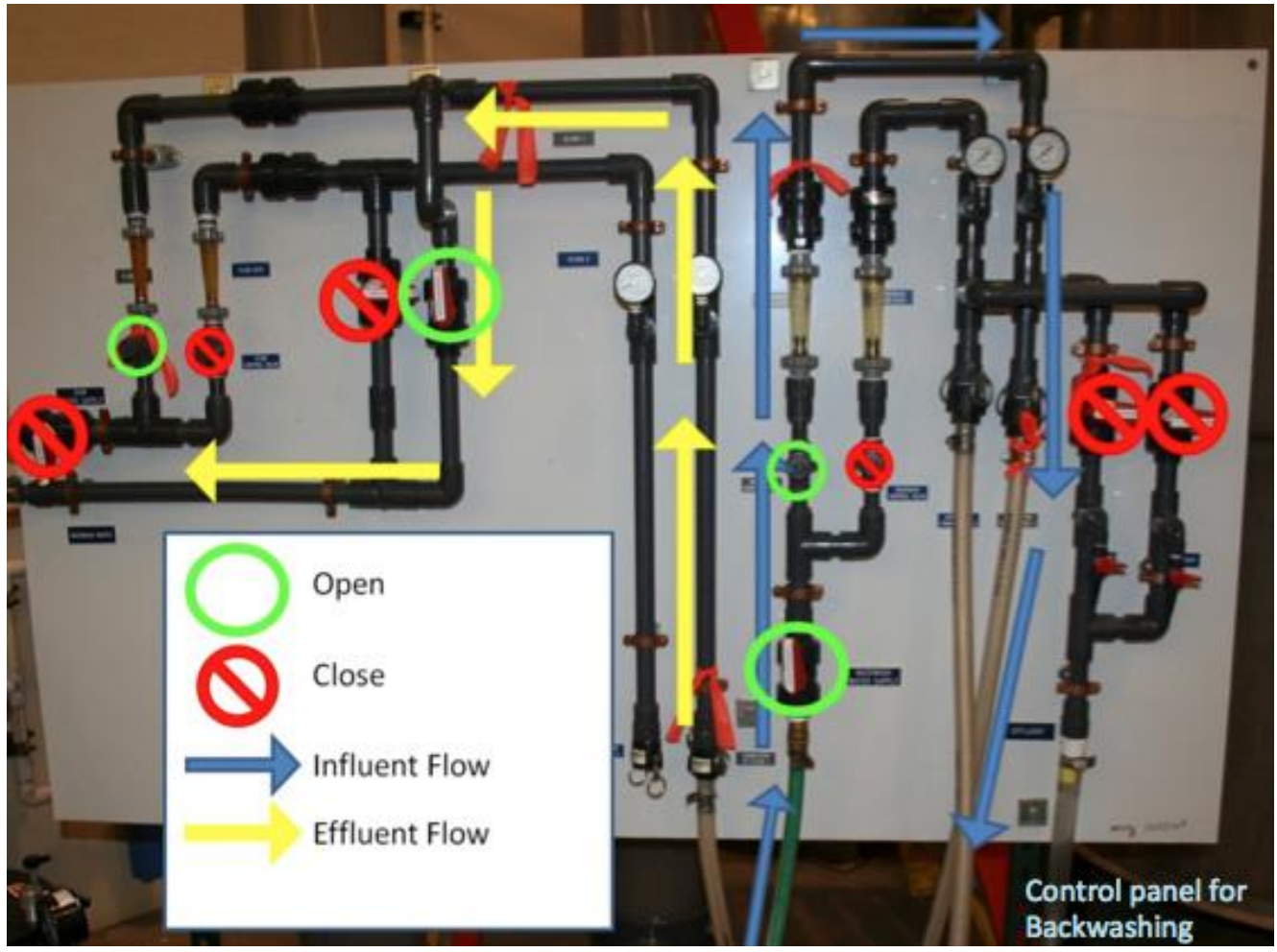

Figure 9. Control Panel and Valve Setting for Backwash 
The water then flows through two columns, The first Column is used for flocculation and has no sand in it. The second column is used for filtering (see Figure 10).

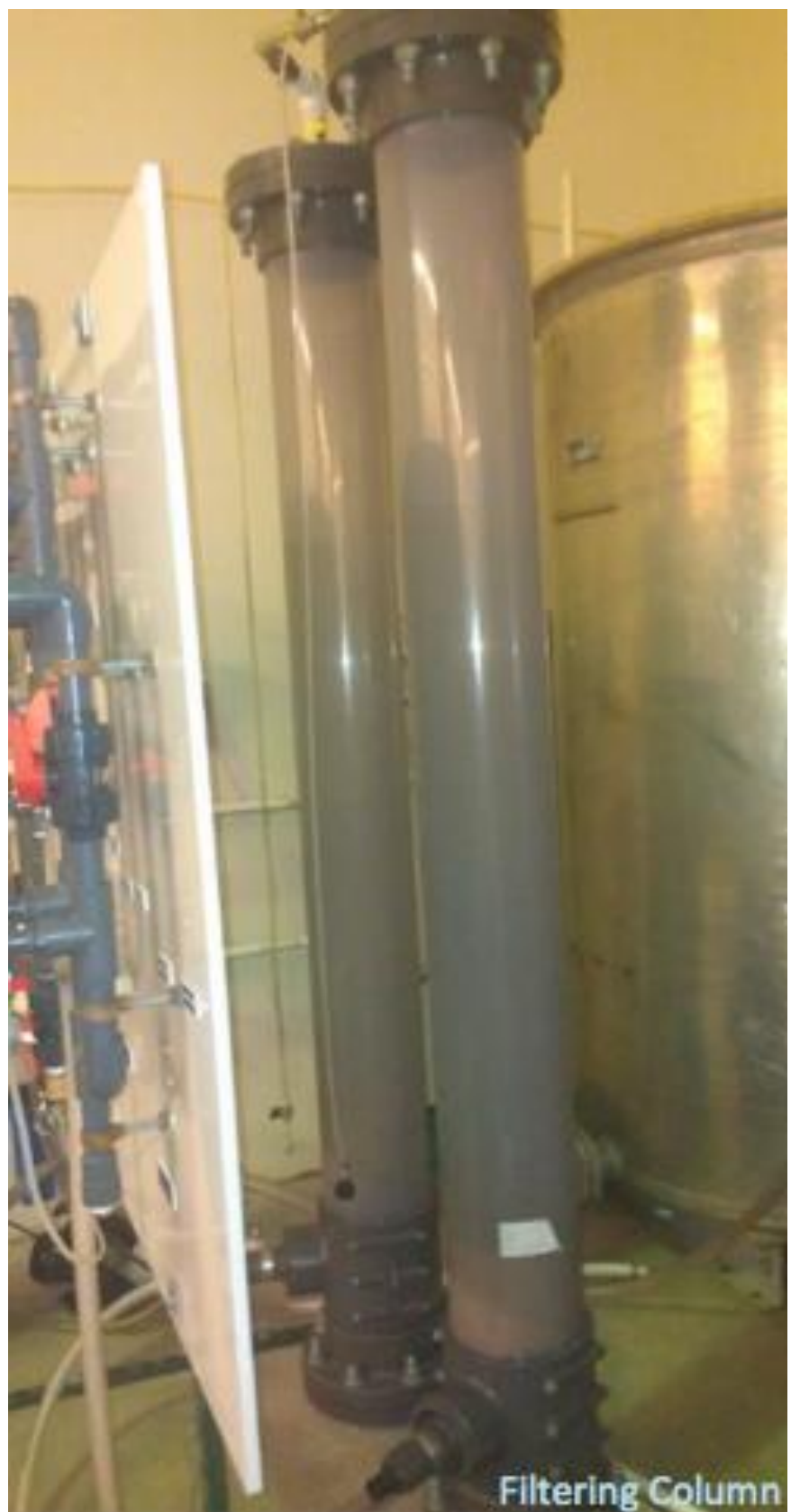

Figure 10. Sand Filtration Unit 
Finally a sample of the effluent will be taken at the sample port and the turbidity of which will get measured using a turbid meter. The effluent will get discharged to the drainage.

\section{(2.3) Laboratory Test, Problems and Modifications.}

A lab manual was developed to instruct the students through the lab. This initial manual is attached in Appendix. This lab manual was used for the 12 groups of students taking the EPSL class in 2012. Most of the students were able to successfully finish the lab. However, there are some problems with both the system and the lab manual.

1. Overall the unit functions well, however, there were some minor problems with the system. The system pump failed once, was replaced immediately and worked well through the semester.

2. Students recorded different data regarding system flowrate and coagulant flowrate. To solve this issue, a table was added to the lab manual asking student record the flowrates throughout the laboratory as well as some other important parameters. In such case an averaged flowrate could be obtained for better result.

3. Instead of giving the students a flowrate for backwashing directly, the students were asked to calculate the backwash flowrate needed to reach $30 \%$ expansion of the sand in the new manual.

4. The students had some difficulties with understanding the parameters involved in direct filtration. More equations and reference materials are 
provided in the manual. More calculation questions were added in the laboratory manual for the student to better understand the design calculations.

5. The Students had difficulties in following the procedures throughout the laboratory. This happens because some of the procedures were not clear to them. In order to solve this issue, filtration cycle was reduced from 3 cycles to 2 cycles. Besides, the students were no longer asked to run the filtration all the way to exhaustion. Instead they were asked to run filtration until effluent exceeds the standard. At the same time, the turbidity of the source water have decreased from $50 \mathrm{NTU}$ to $15 \mathrm{NTU}$ in order to be consistent with real life treatment.

6. In order to obtain more accurate result for analysis, the column for flocculation was taken off the system. Flocculation and filtration then both take place in the second column. This on the other hand will speed up the lab by reducing dead volume.

\section{(3) Results and Future Work}

As a response to the problems listed above, modifications have been made to the laboratory manual and a newer version have been generated as is attached in Appendix. Even that the current direct filtration system is mature enough for current use, there is

still space for enhancement. For the next couple of years, the topics listed below might be a good direction to further work on the system.

1. Filtration media should be provided for the system. Physical and Chemical parameters will be provided for calculations 
2. Additional smaller columns might be added to the unit in order to provide the students opportunities to compare the performance of direct filtration at different parameters such as media size, bed length, coagulant dosage. Different filter media might be provided for students to compare with sand. This will also enable the students to choose their own filter media when dealing with a specific pollution scenario. Typical media used for direct filtration include sand, anthracite and GAC.

3. Two groups of students might work together each week to run multiple filtrations with different media parameters including media sizes, depth, and filtration rates. Specific deposit at breakthrough and head loss increase rate constant could be calculated. This will enable the students to obtain design parameters through a multivariable regression, and thus let them be able to work on a real life design questions that will be added to the questions section. Detailed procedure is discussed previously at run length determination part.

4. It is advised that specific assignments of different pollution scenarios are given to different groups of students. For each assignment, students should be able to design their own process flow using the existing units to treat different pollutants as assigned. 


\section{Acknowledgements}

The author would like to thank his advisor as well as committee for their help, encouragement, and instruction along the way. Special thanks are also owed to David Perram and Zeyad Ahmed for their help through out the system fabrication and report writing. I would like to recognize the contribution of my parents, without whose encouragement and financial support, the author would not be able to finish his degree. I would also like to thank the faculty and staff of MTU CEE department for their help and education throughout my master's degree. I would like to thank all my friends for the time we spend together. Lastly but certainly not least, I would like to thank my family and wife, Qin Ma, for her support and encouragement, and for putting up with me along the way. 


\section{References}

Hand, D.W., C. Wojick, and C.R. Baillod., NSF Proposal for the EPSC Center., Michigan Technological University. 2000.

Hand, David W., CEE 4509 - Environmental Process \& Simulation Laboratory Course Syllabus., Department of Civil and Environmental Engineering, Michigan Technological University. Spring, 2011.

Bjøirnar Eikebrokk, Coagulation-direct filtration of soft, low alkalinity humic waters, Water Science and Technology, Volume 40, Issue 9, 1999, Pages 55-62

Christian Psoch, Silke Schiewer, Direct filtration of natural and simulated river water with air sparging and sponge ball application for fouling control, Desalination, Volume 197, Issues 1-3, 2 October 2006, Pages 190-204, ISSN 0011-9164, 10.1016/j.desal.2005.11.027.

Raveendra Babu and Malay Chaudhuri, Home water treatment by direct filtration with natural coagulant, Journal of Water and Health, Volume 03, Issue 1, 2005, Pages 27-30

Naomi L. Tillison, David W. Hand, Hands-On Learning of Water Treatment Design, Department of Civil and Environmental Engineering Michigan Technological University, 2005 Burns, Susan K.; Adams, V. Dean; and Maloney, Steel B., "Direct Filtration Versus Conventional Water Treatment in the Intermountain Region" (1984). Reports. Paper 580. Hutchison, W. R. (1976), High-rate direct filtration, Amer. Wat. Works Assoc., 68(6), 292 Crittenden, John C., David W. Hand et al., Water Treatment: Principles and Design. MWH, 2005 


\section{Appendix:}

\section{Initial Lab Manual}

\section{CE4509 Environmental Process and Simulation Laboratory}

Procedure to Operate and Analyze a Direct Filtration Sand Filter

Department of Civil and Environmental Engineering

Michigan Technological University

\section{Objectives}

The objectives of this laboratory include:

- Become able to operate the Direct Filtration apparatus and use which to treat water with high turbidity.

- Determine optimal ratio of variable to system pump flow rate and use which to determine the optimum coagulant dosage.

- Determine breakthrough time for the optimum coagulant dosage, plot the breakthrough profile

- Determine breakthrough time for back washing and plot the breakthrough profile 


\section{Background}

Direct filtration is a water treatment technology that combines coagulation and filtration to remove the turbidity and color matter of the water. Unlike coagulation, it is only suitable for treating water with a turbidity of less than 10 NTU (Janssen et al. 1986). Key features of direct filtration include reduced capital and O\&M cost, high final water quality with turbidity lower than 0.1 NTU, large capacity up to 150 $\mathrm{gpm}$. It normally consists of four major systems: inflow, coagulant introduction and mixing, flocculation, filtration and outflow. Theoretically, water flows into the system, enters a rapid mixing system followed by the introduction of coagulant, and there flocculation occurs, little particles are generated and flocs are formed. The flocs then get removed as suspended particles flow through a dual or monomedia granular filter. A typical process train for treatment of surface water by direct filtration is shown below. (MWH, Water Treatment, Figure 4-5, 265).

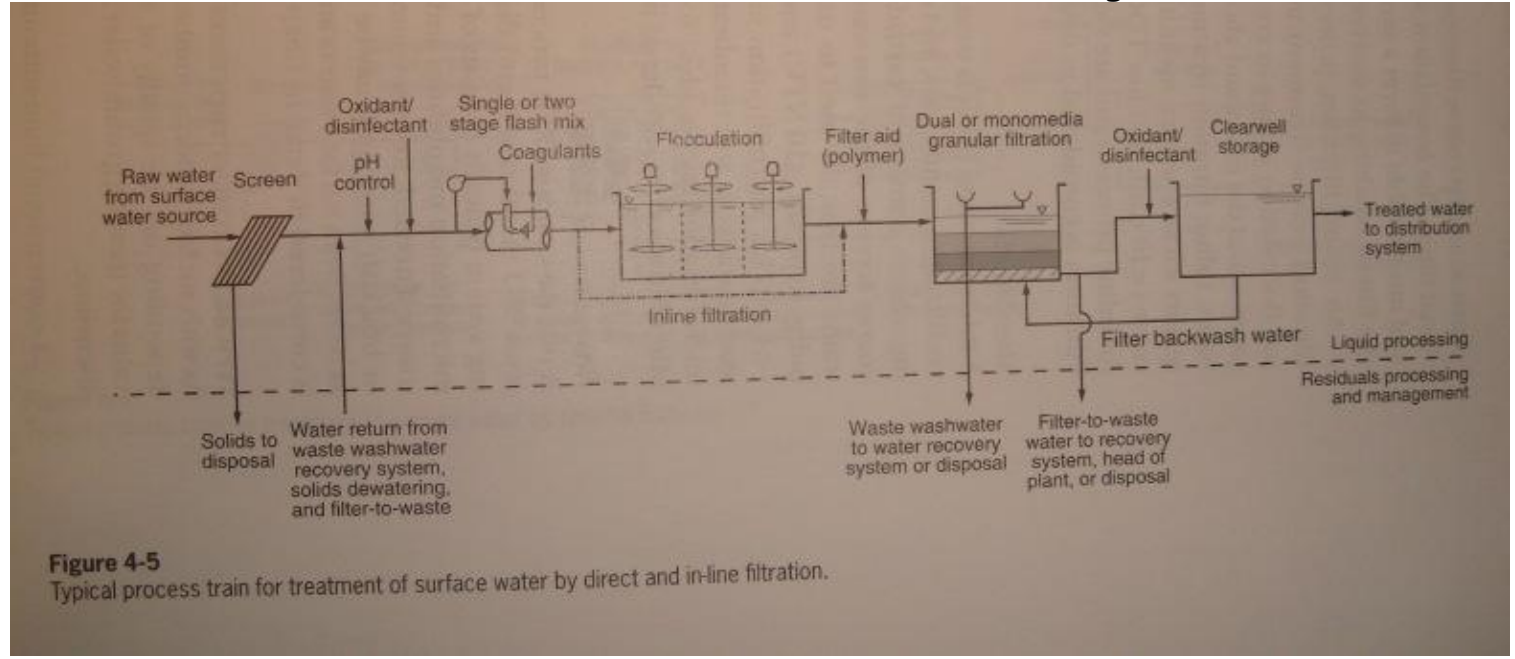

Figure 11. Typical process train for treatment of surface water by direct filtration

The direct filtration process follows a four-stage cycle: filter ripening, effective filtration, breakthrough, and backwashing (see Figure 2). Ripening is a process of media conditioning in which as the particulates buildup on the clean media the media becomes more efficient at collection. Ripening immediately follows backwashing. It allows the filter media to settle in the columns in order to avoid turbidity spikes once the system is started. During the effective filtration stage, the filter is functioning with an acceptable effluent turbidity level. As the filter continues to collect particles, it will eventually become exhausted and no longer filters effectively, and turbidity will increase. This increase in turbidity is a sign of breakthrough. Once breakthrough occurs, a backwashing cycle is necessary. Backwashing is the process of forcing clean water (tap water in our case) through the filter in the reverse direction to stir up the filter media and remove the 
various particles. Since backwashing requires the system to be taken offline, efficient backwashing is a critical step in direct-filtration.

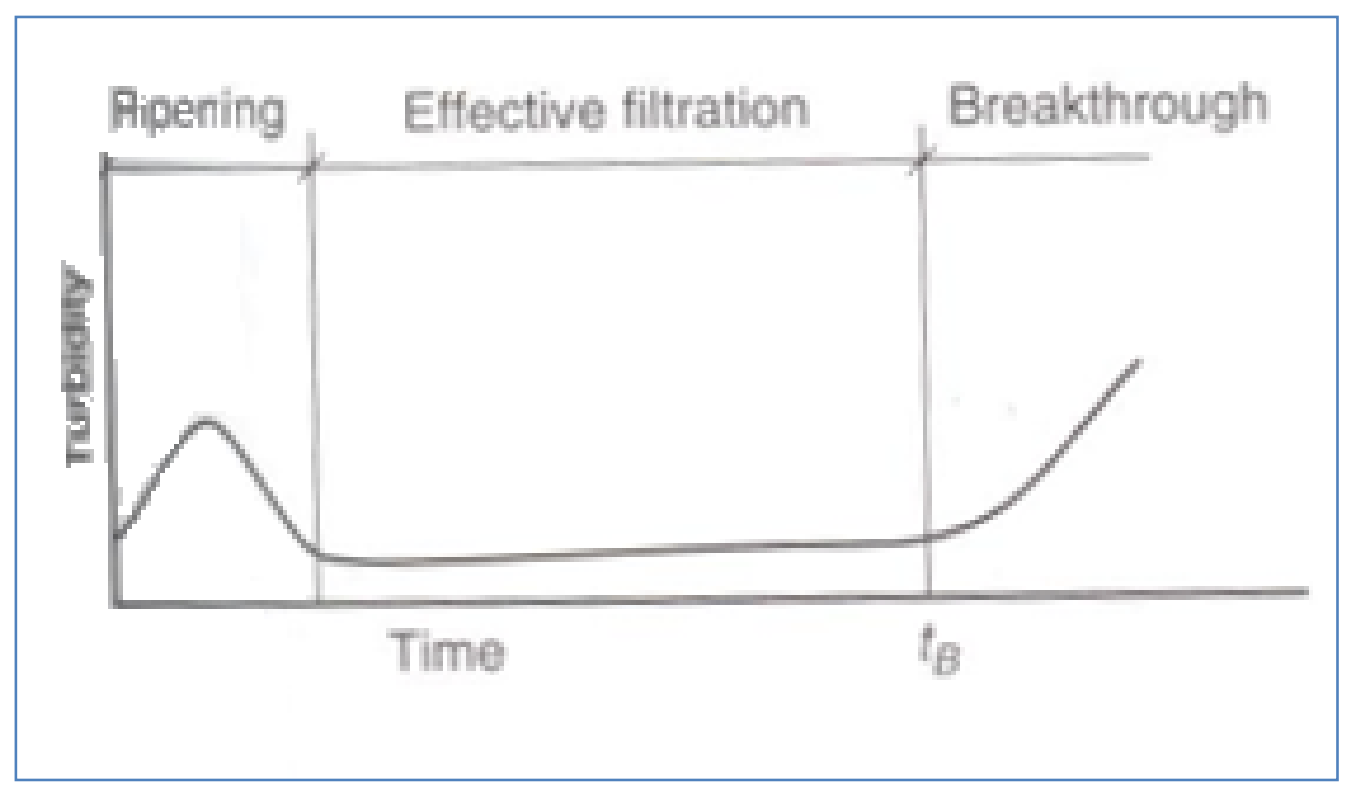

Figure 12. Turbidity versus time for a direct filtration system 


\section{Lab setup:}

The lab set-up can be described as is shown in the flown chart below.

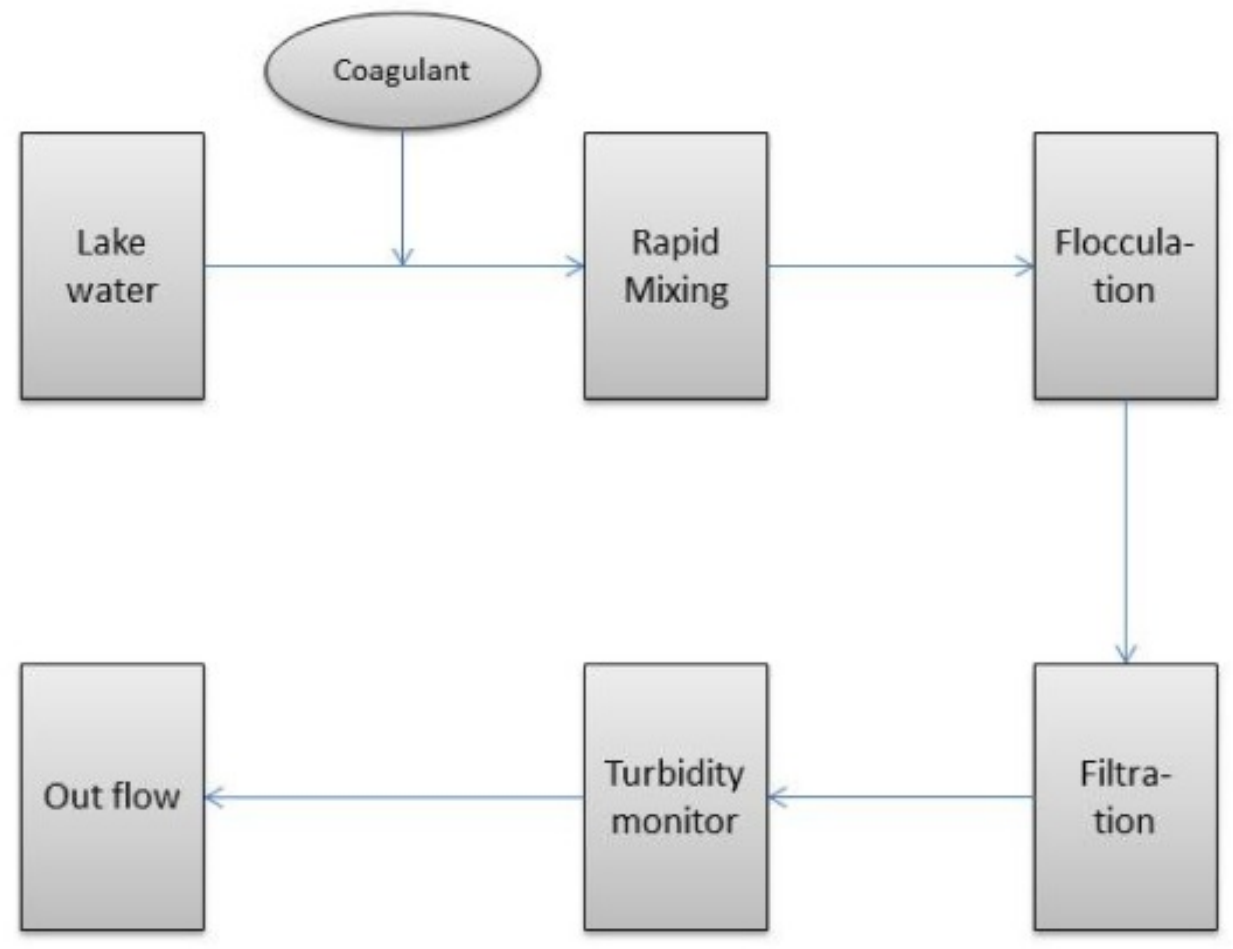

Figure 13. Simplified flow chart of a direct filtration system 
The lake water will be spiked and totally mixed in a stainless steel tank with bentonite to serve as our inflow. Mixing is fulfilled by circulating the water from bottom to top of the tank, as is shown in the pic below:

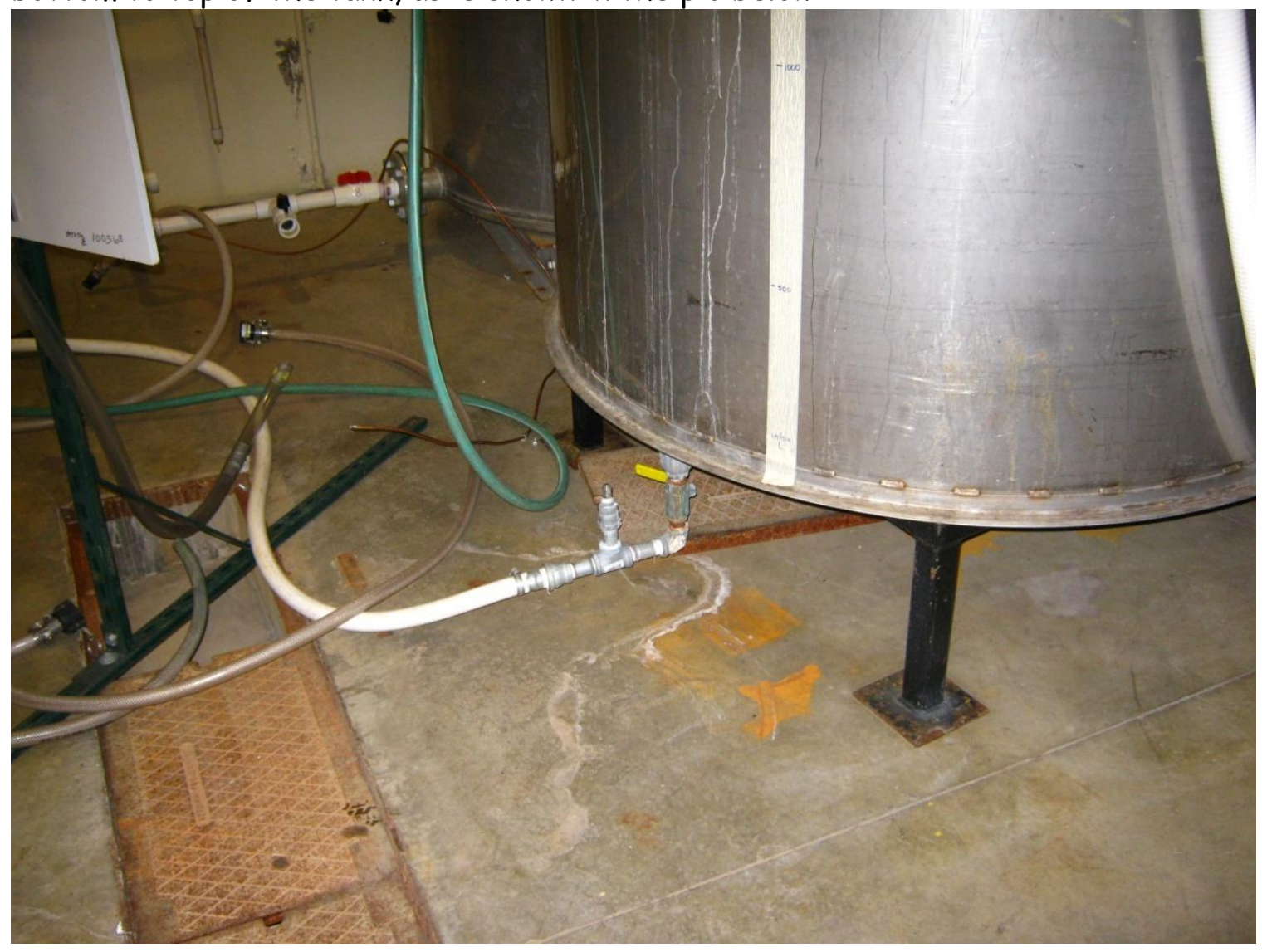

After mixing with bentonite, the coagulant will be introduced to the system and get mixed through a packing tank, as is shown below. 


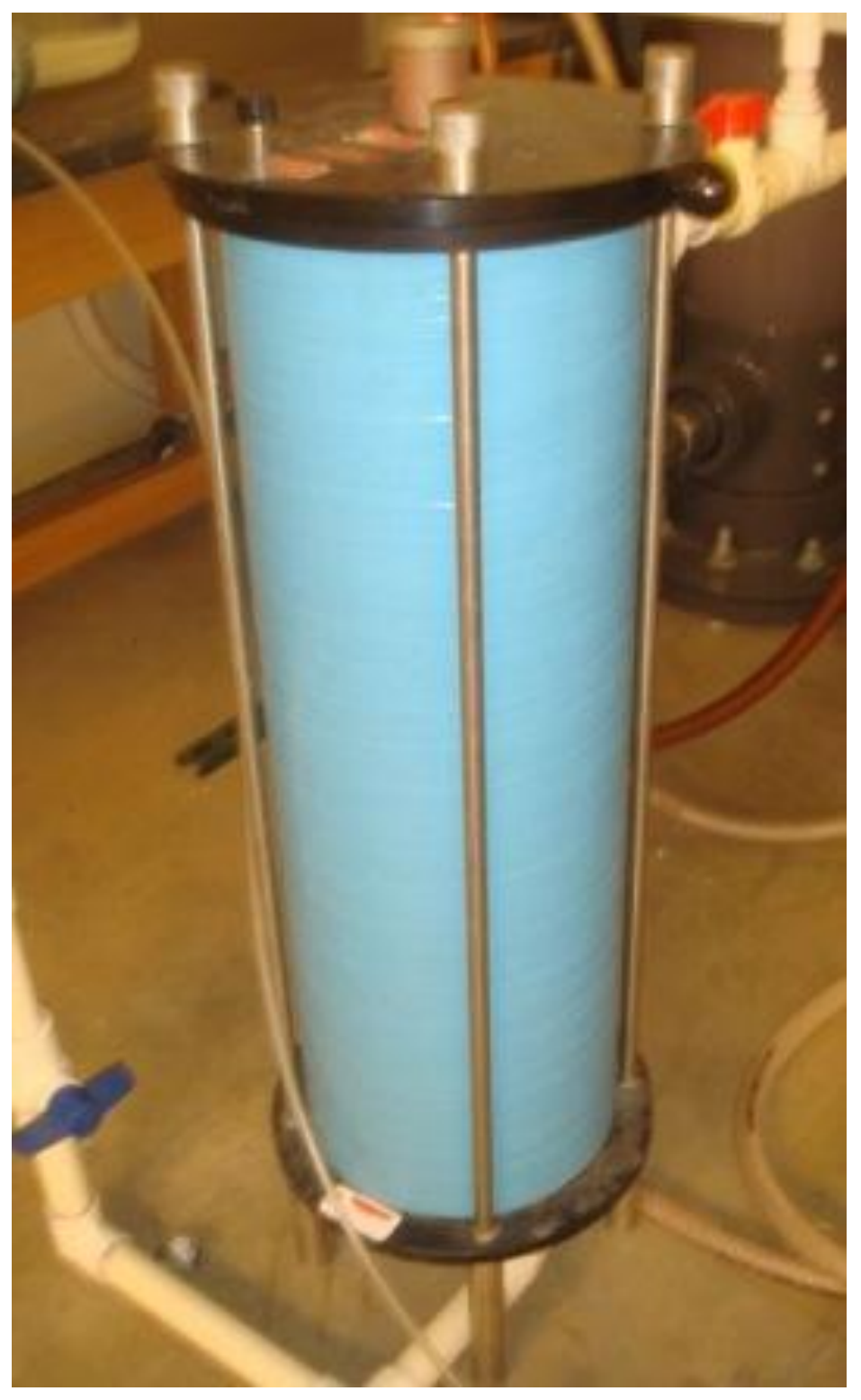

The control panel navigates the water to the right system, and through adjusting valves, back washing and direct filtration can be achieved. The flow of water and set up of valves for each process are shown in the pics below: 

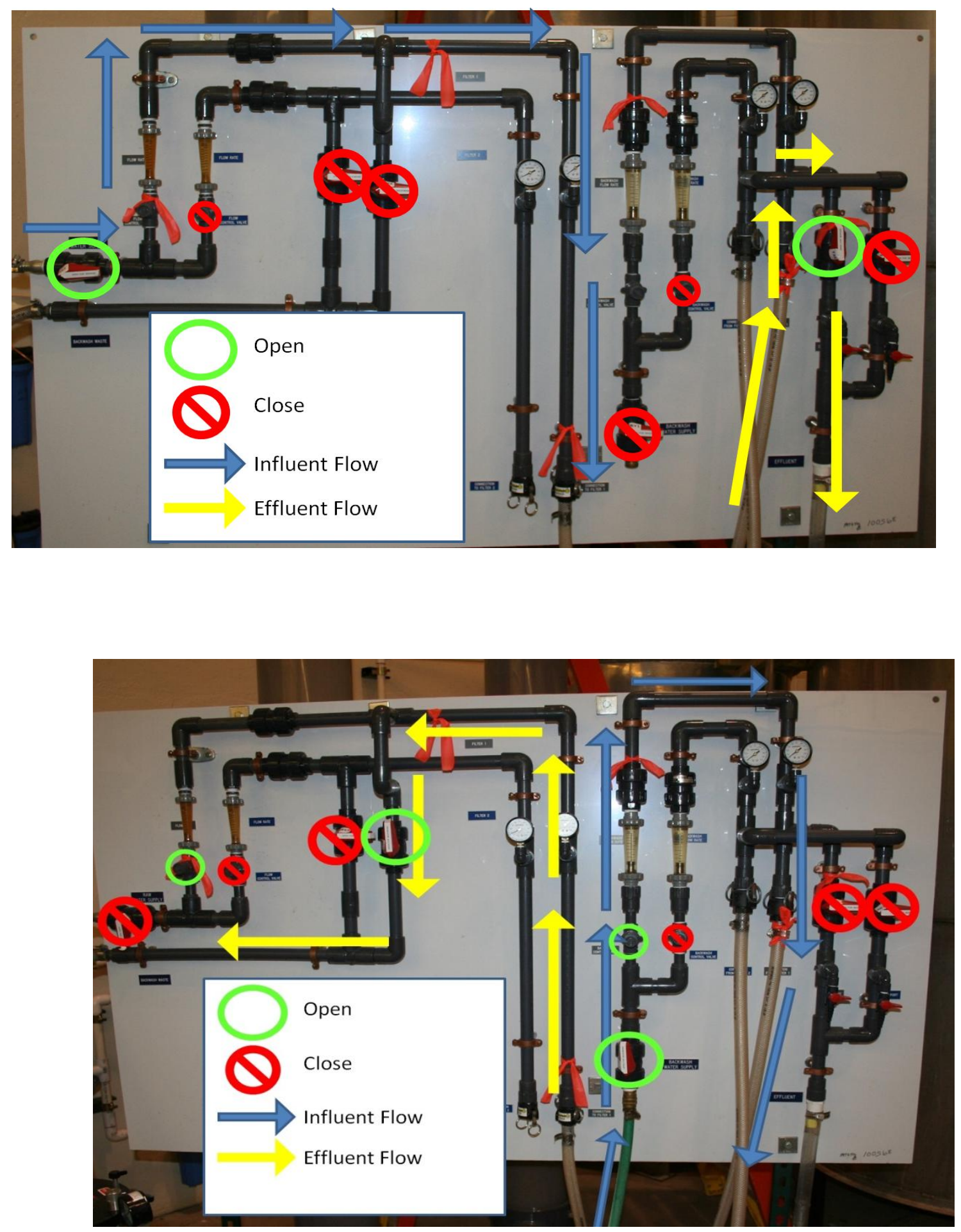
Finally the turbidity of the effluent will get measured at the inline turbimeter, after which the water will get discharged to the drainage.

\section{Procedure:}

Week 1:

1. Check the direct filtration apparatus; get familiar with all the valves and get ready to operate the two processes.

2. Calculate the volume of lake water needed using a flow rate of $2.4 \mathrm{~L} / \mathrm{min}$, spike the lake water with bentonite to create a turbidity of 50 NTU.

3. Measure the turbidity of tap water and the final lake water. Triplicates shall be conducted for both

4. Switch the valves to proper position for back washing. Perform backwashing until the turbidity of the effluent is lower than 1 NTU. Measure and record the turbidity of effluent every half a minute for the first 5 minutes, and every minute after 5 minutes. For the back washing, use a flowrate of $3 \mathrm{~L} / \mathrm{min}$

Week 2:

1. Prepare $10 \mathrm{~L}$ of $0.2 \mathrm{~g} / \mathrm{L}$ Aluminum sulfate solution.

2. Mix the tank using the circulating pump for 5 minutes. Take 3 samples from the sample port and 3 from the top of the tank, measure the turbidity to make sure the water have been well mixed

3. Turn on the system pump with the valves set for filtration. Adjust the angle of the valve next to the pump to create a flowrate of $2.4 \mathrm{~L} / \mathrm{min}$. Mark this angle and you will use it later for this lab. Adjust the FMI pump to create a flowrate of $150 \mathrm{ml} / \mathrm{min}$.

4. Switch the valves on the control panel to backwashing mode. Perform back washing with the maximum flowrate until the turbidity of effluent is lower than 1 NTU. Record the values every half-minute. Determine the flowrate.

5. Set up the system for filtration. The valves shall be adjusted in the proper position so that the flowrate stay the same with step 3. Record turbidity of effluent samples every half-minute during the first 5 minutes and every minute afterwards. Measure the actual flowrate.

6. Clean up everything in the lab zone, flush the system under backwashing mode. Turn the valves to proper position so that the water doesn't leak.

7. Repeat step 4, then decrease the flowrate of coagulant to 0 and start filtration again. This gives the breakthrough profile with no coagulation, just filtration. 


\section{Data Analysis and questions:}

1. Plot the breakthrough curve for the filtration, with and without coagulation. Compare the two curves, explain why.

2. Compare the common treatment methods for turbidity for the advantages and disadvantages.

3. List common situations where direct filtration method is applied.

4. Other than the dosage of coagulant and the filtering material, what else can you think of that can affect the performance of a direct filtration apparatus and explain how do they affect it.

5. What parameters do you need for designing a direct filtration system for a real world application and how do you use these parameters for your design?

6. List things that you think need to be done that can improve this lab. 


\title{
Final Lab Manual
}

\author{
CE4509 Environmental Process and Simulation Laboratory \\ Procedure to Operate and Analyze a Direct Filtration Sand Filter \\ Department of Civil and Environmental Engineering \\ Michigan Technological University
}

\section{Objectives}

The objectives of this laboratory include:

- Become able to operate the Direct Filtration apparatus and use it to treat lake water.

- Determine breakthrough time for the optimum coagulant dosage, plot the breakthrough profile to predict the filter performance.

- Understand the basic theory of direct filtration and become able to do obtain the data required to design a direct filtration unit.

\section{Background}

\section{Coagulation and flocculation}

Negative charges on particles in most natural water create repulsive forces between particles and prevent them from attaching to each other or settling. Coagulation is a process of destabilizing suspended particles by adding coagulants, which empart positively charged ions in water to neutralize the negative charge on the surface of the particles. Following coagulation, flocculation increases the probability of contacts between suspended matters by introducing hydraulic gradients. Particles then flocculate and grow large enough to settle out by gravity. Coagulation and flocculation are used when the water body has a high turbidity, which has aesthetic effects of drinking water.

\section{Flow Filtration Mechanism and Direct Filtration Process}

There are basically four filtration mechanisms, Sedimentation, Interception, Inertia and Brownian Diffusion:

Sedimentation: the mechanism of sedimentation refers to the filtration when the gravity force and the associated settling velocity of the particle cause it to reach to the collector. 
Interception: when following the streamline, if a large enough particle lies close enough to the filter media surface, and hit on the media grain, it will get captured. This mechanism is called interception.

Inertia: inertia refers to the situation when larger particles move fast enough to travel off their original streamlines and hit on media grains.

Brownian Diffusion: very small particles like viruses travel randomly within the fluid due to thermal gradients. When there's diffusion for the particle towards median grains, it is called Brownian diffusion. Note this is only important to small particles with diameters less than 1 micron.

Rapid filtration is a water treatment technology that removes suspended matters in water by running water through a filter media. Besides straining, particles are removed when they adhere to the filter grains or deposited particles.. When the water is pretreated with coagulant addition and flocculation before filtration, the process is called direct filtration. Direct filtration is normally suitable for treating water with a turbidity of less than 15 NTU. Key features of direct filtration include reduced capital and O\&M cost, and high final water quality with turbidity lower than 0.1 NTU. Direct filtration normally consists of five major processes: inflow, coagulant introduction, flocculation, filtration and outflow. Water flows into the system, enters a rapid mixing system after the introduction of coagulant where flocculation occurs. The flocs then get removed as suspended particles flow through a dual or monomedia granular filter. A typical process train for treatment of surface water by direct filtration is shown below. (MWH, Water Treatment, Figure 4-5, 206).

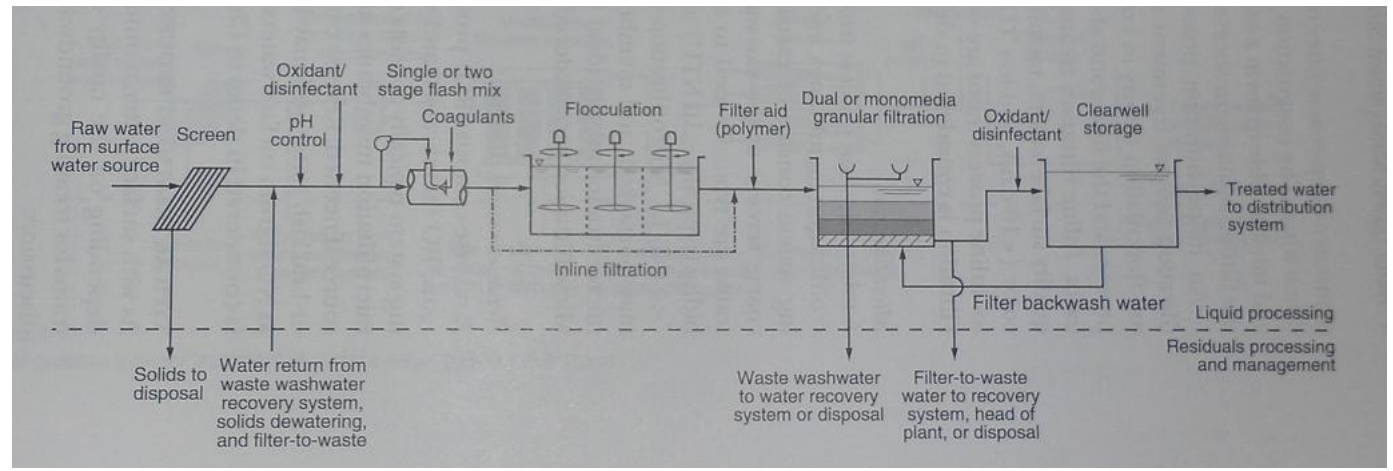

Figure 1. Typical Process Train for Treatment of Surface Water by Direct Filtration

\section{Calculations}

The direct filtration process follows a four-stage cycle: filter ripening, effective filtration, breakthrough, and backwashing (see Figure 2). Ripening is a phase of 
media conditioning in which as the particulates buildup on the clean media the media becomes more efficient at collection. It allows some particles to pass through the filter media and creates up to two turbidity spikes. During the effective filtration stage, the filter is functioning within an acceptable effluent turbidity level. As the filter continues to collect particles, turbidity and head loss will both increase, resulting in the effluent exceeding the NTU limit or the head loss reaching the system limit head. Both of these results indicate breakthrough. Once breakthrough occurs, a backwashing cycle is necessary. Backwashing is the process of forcing clean water (also known as "wash" water) through the filter in the reverse direction to stir up the filter media and remove the various particles. Since backwashing requires the system to be taken offline, efficient backwashing is a critical step in direct-filtration. Ripening immediately follows backwashing and that completes a whole cycle. Calculation involving each part will be discussed below. Students are required to review Chapter 11 in textbook for detailed explanation.

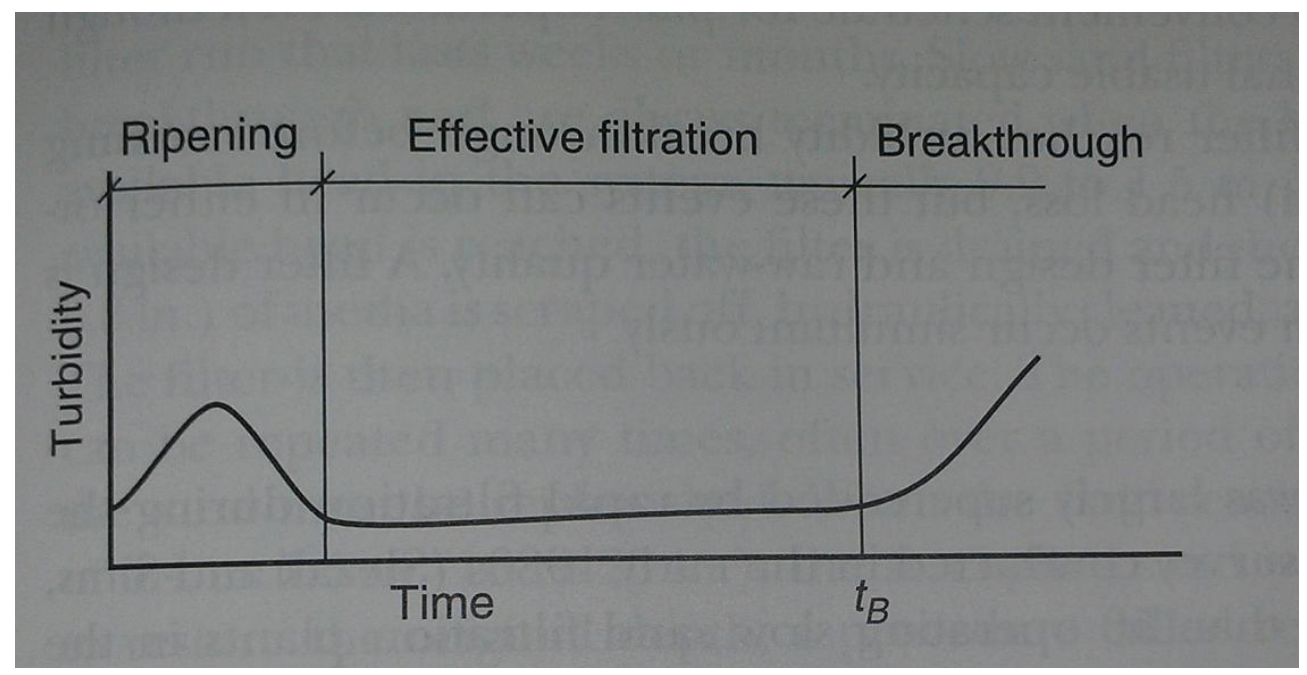

Figure 2. Effluent Turbidity Profile of Direct Filtration Process

\section{Filter media}

During ripening and effective filtration stage, the properties of the filter media can greatly affect the time to breakthrough or time to limit head.

Effective Size (ES): "the media grain diameter at which 10 percent of the media by weight is smaller, as determined by a sieve analysis." (MWH, Water Treatment 2012) 


$$
E S=d_{10}
$$

WhereES = effective size

$$
d_{10}=10^{\text {th }} \text { percentile media grain diameter, } \mathrm{mm}
$$

Uniformity Coefficient (UC): a coefficient that describes the uniformity of the granular media. When the filter media are of the same size, UC=1. Practically, UC> 1 and the smaller the UC is, the better the uniformity of the granular media.

$$
U C=\frac{d_{60}}{d_{10}} \quad(11-1)
$$

Where $d_{60}=60^{\text {th }}$ percentile media grain diameter, $\mathrm{mm}$

Granular Bed Porosity $(\varepsilon)$ : the ratio of void bed space over the total bed volume. The bed porosity has a great impact on head loss and filtration effectiveness.

$$
\varepsilon=\frac{V_{t}-V_{m}}{V_{t}}=\frac{V_{v}}{V_{t}}
$$

Where $=$ porosity, dimensionless

$$
\begin{aligned}
& V_{t}=\text { total volume in media bed, } \mathrm{m}^{3} \\
& V_{v}=\text { void volume in media bed, } \mathrm{m}^{3} \\
& V_{m}=\text { volume of media, } \mathrm{m}^{3}
\end{aligned}
$$

\section{Hydraulics of Flow}

Reynolds Number $(\mathrm{Re})$ : the ratio of inertial movement over viscous movement.

$$
\begin{aligned}
& \qquad \operatorname{Re}=\frac{\rho_{\mathrm{f}} \mathrm{VL}}{\mu_{\mathrm{f}}} \quad(11-8) \\
& \text { Where } \rho_{\mathrm{w}}=\text { fluid density, } \mathrm{kg} / \mathrm{m}^{3} \\
& v=\text { filtration rate (superfacial velocity), } \mathrm{m} / \mathrm{s} \\
& \mu=\text { dynamic viscosity of fluid, } \mathrm{kg} / \mathrm{ms} \\
& d=\text { media grain, } \mathrm{m}
\end{aligned}
$$

Clean Bed Head-loss: the theoretical head-loss of the clean bed can be calculated using the equation below: 


$$
H_{L}=\kappa_{V} \frac{(1-\varepsilon)^{2}}{\varepsilon^{3}} \frac{\mu L v}{\rho_{W} g^{2}}+\kappa_{I} \frac{1-\varepsilon}{\varepsilon^{3}} \frac{L^{2}}{g d}
$$

Where $H_{L}=$ Clean head loss across media bed, $m$

$\mathrm{K}_{\mathrm{v}}=$ head loss coefficient due to viscous forces, unitless

$\mathrm{K}_{\mathrm{I}}=$ head loss coefficient due to inertial forces, unitless

Porosity of Expanded Bed: during backwashing, a lot of times the bed needs to be expanded to clean the exhausted bed better. When the bed expands, the porosity changes, and the expanded porosity of the bed can be calculated using the equation below:

$$
\frac{L_{E}}{L_{F}}=\frac{1-\varepsilon_{F}}{1-\varepsilon_{E}} \quad(11-15)
$$

Where $L_{E}=$ depth of expanded bed, $m$

$$
\begin{aligned}
& L_{F}=\text { depth of fixed bed, } m \\
& \varepsilon_{F}=\text { porosity of expanded bed, dimensionless } \\
& \varepsilon_{F}=\text { porosity of fixed bed, dimensionless }
\end{aligned}
$$

Backwash Flowrate: the backwash flowrate needs to reach a certain percent of expansion can be calculated using the equation below:

$$
v=\frac{\mu R e}{\rho_{W} d}=\frac{\mu}{\rho_{W} d}\left(\frac{-\kappa_{V}(1-\varepsilon)}{2 \kappa_{I}}+\frac{1}{2 \kappa_{I}} \sqrt{\kappa_{V}^{2}(1-\varepsilon)^{2}+4 \kappa_{I} \beta}\right)
$$

Where $\beta=$ backwash calculation factor, dimensionless

$$
\beta=\frac{g \beta_{W}\left(\beta_{P}-\beta_{W}\right) d^{3} \varepsilon^{3}}{\mu^{2}} \quad(11-20)
$$


Multimedia filters: when there's more than one layer of filters, in order to make sure that all media fluidize at the same backwash rate, the densities of these media need to follow the equation below:

$$
\frac{d_{1}}{d_{2}}=\left(\frac{\rho_{2}-\rho_{W}}{\rho_{1}-\rho_{W}}\right)^{0.625} \quad(11-25)
$$

Whered $d_{1}=$ grain diameter of media $1, m$

$$
\begin{aligned}
& d_{2}=\text { grain diameter of media } 2, \mathrm{~m} \\
& \rho_{1}=\text { density of medium } 1, \mathrm{~kg} / \mathrm{m}^{3} \\
& \rho_{2}=\text { density of medium } 2, \mathrm{~kg} / \mathrm{m}^{3}
\end{aligned}
$$

Failure to choose the right media may cause one media to be washed out while fluidizing the other one.

\section{Determination of Run Length}

A simplified steady-state phenomenological model has been developed to predict the run length of effective filtration. Breakthrough occurs either when the effluent reaches the turbidity limit, or the head loss reaches the limit head. They can be calculated using the equation below:

$$
\begin{gathered}
t_{B}=\frac{\sigma_{B} L}{v_{F}\left(C_{o}-C_{E}\right)} \\
t_{H L}=\frac{\left(H_{T}-h_{L, O}\right) L}{k_{H L} v_{F}\left(C_{o}-C_{E}\right)}
\end{gathered}
$$

Where $t_{B}=$ time to breakthrough, $h$

$\sigma_{B}=$ Specific deposit at breakthrough, $\mathrm{mg} / \mathrm{L}$

$L=$ filter bed depth, $m$

$C_{0}=$ influent concentration, $\mathrm{mg} / \mathrm{L}$

$C_{e}=$ effluent concentration, $\mathrm{mg} / \mathrm{L}$

In the equations above, $\sigma_{B}$ and $k_{H L}$ can be obtained through pilot study. When several direct filtration runs are conducted with different media sizes, filtration rates and depths, $C_{O}, C_{E}, t_{B}, h_{L, O}$, and $h_{L}$ are recorded at time $t_{B}$, and $\sigma_{B}$ and $k_{H L}$ can be calculated using equation 11-58 and 11-61. A multivariate regression analysis can 
help determine the relationship between $\sigma_{B}, k_{H L}$ and $h, v, E S$. Use the relationship to calculate $\sigma_{B}$ and $k_{H L}$ for the real world filtration plant and predict the run length with the given filter media.

\section{Lab setup:}

The lab set-up can be described by the flow chart below.

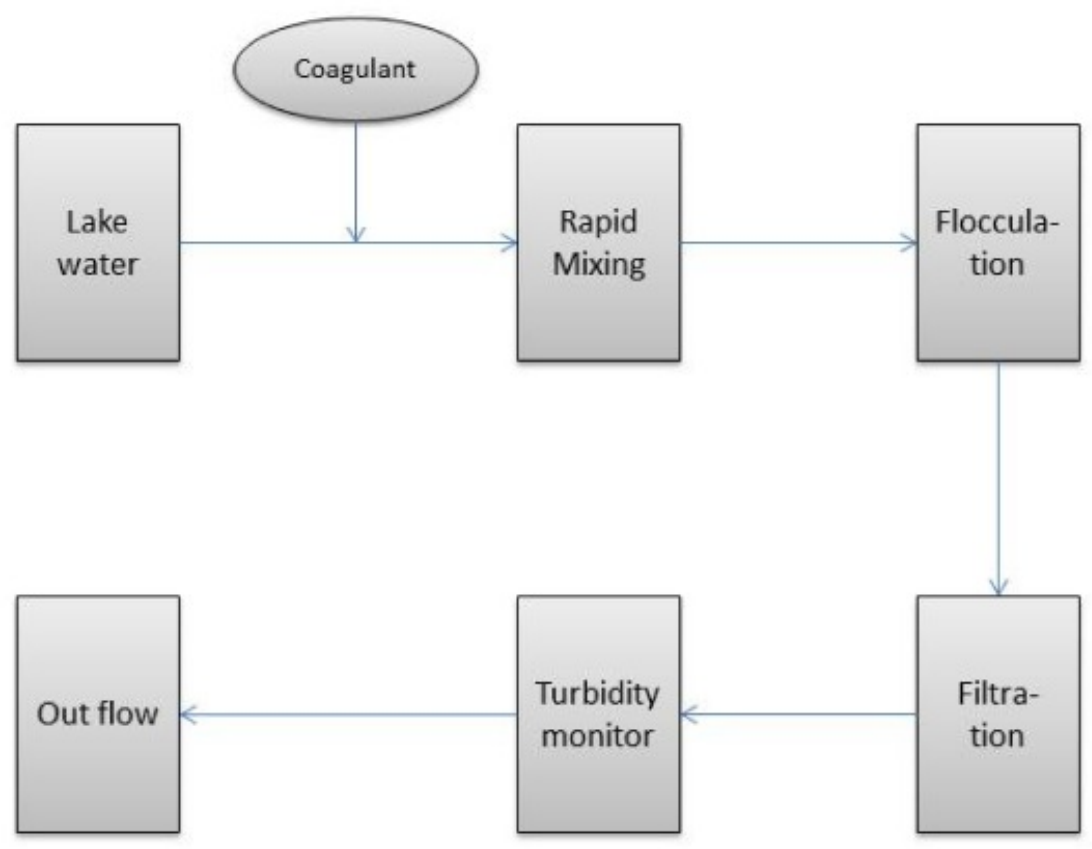

Figure 3. Simplified Flow Chart of the Direct Filtration System 


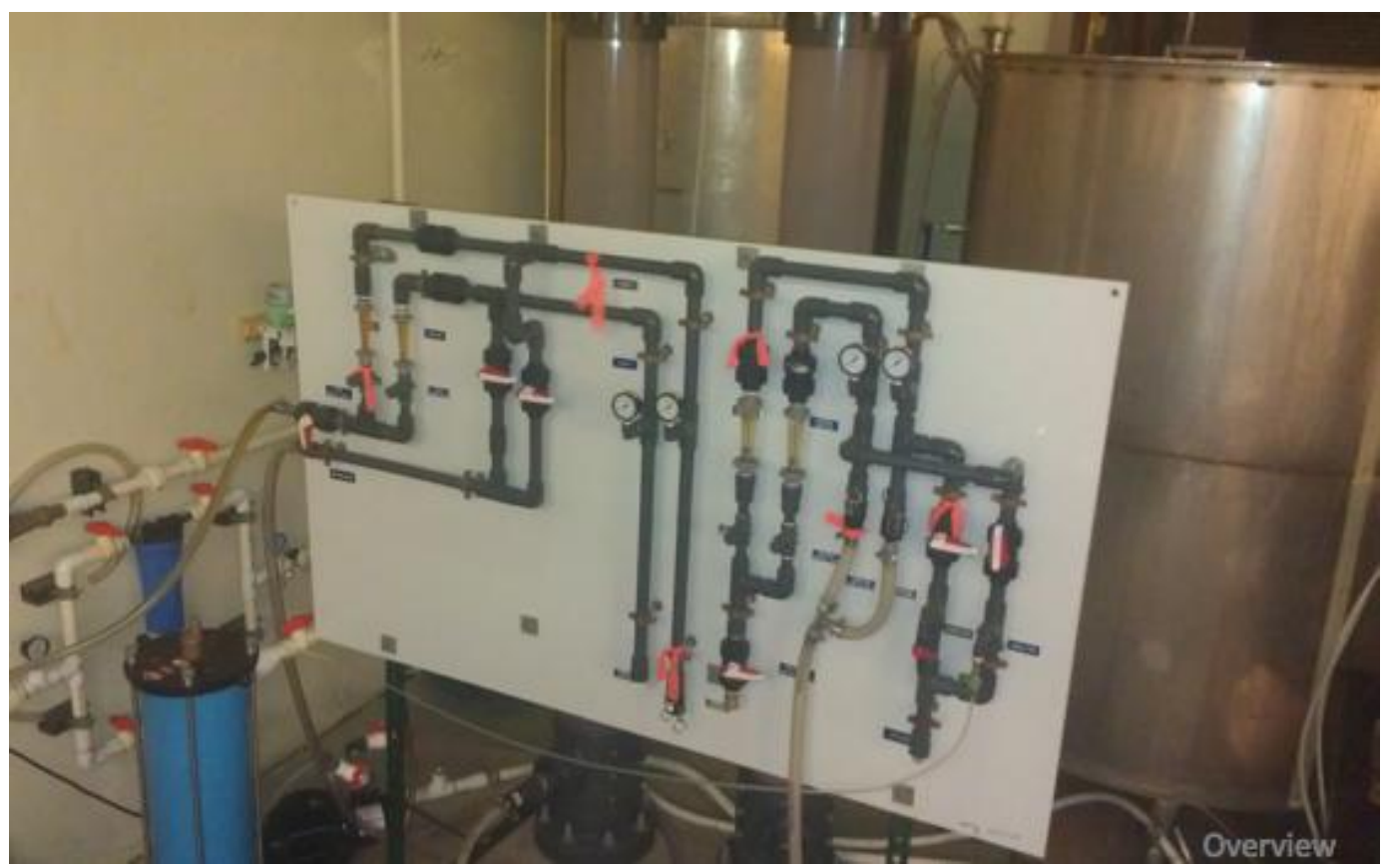

The lake water will be spiked and totally mixed in a stainless steel tank with bentonite to serve as our inflow, as is shown in the pic below. Mixing is fulfilled by circulating the water from bottom to top of the tank:

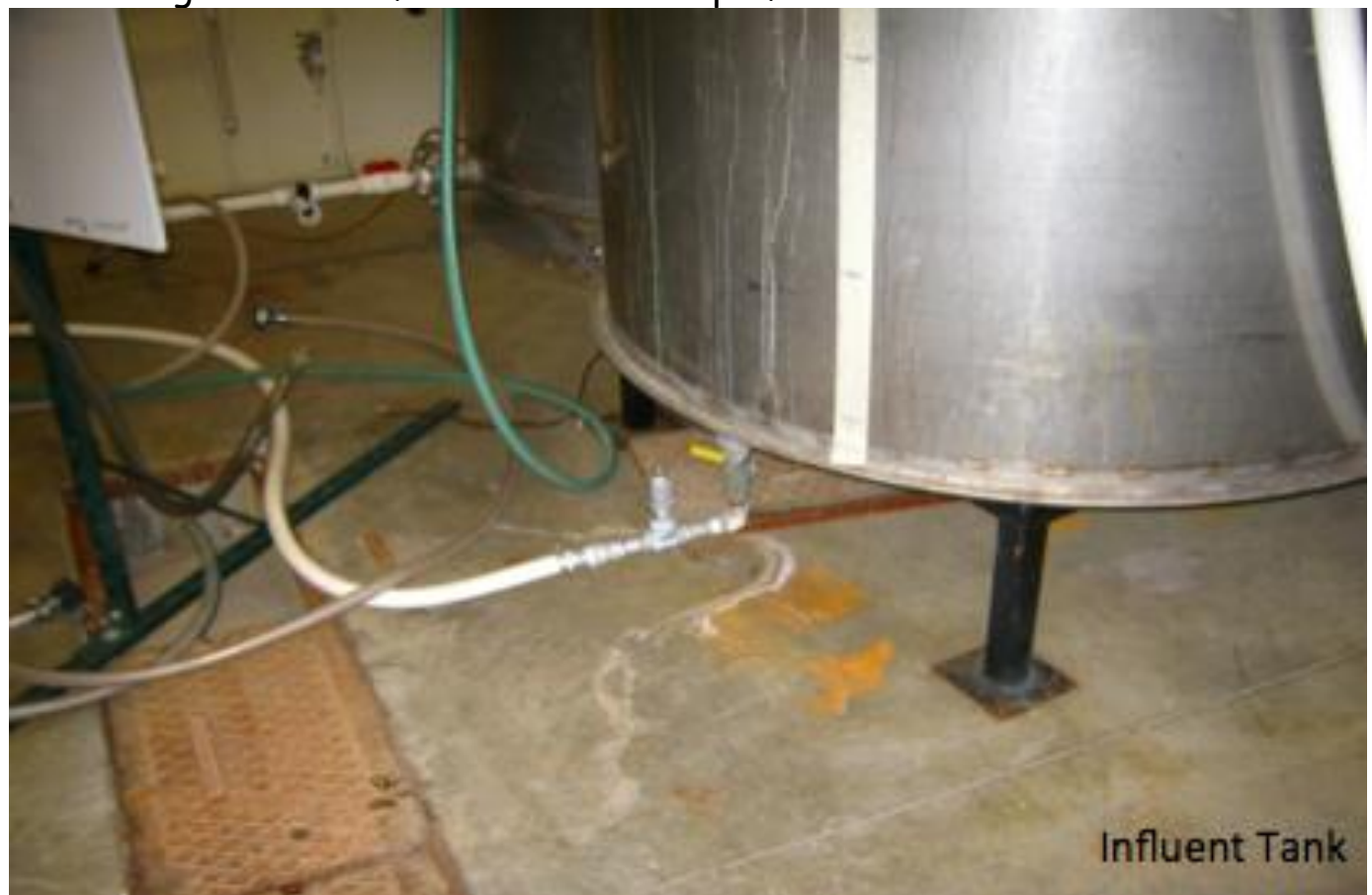

After mixing with bentonite, the coagulant will be introduced to the system with a FMI pump at desired flowrate and get mixed through a packing tank, as is shown below. 

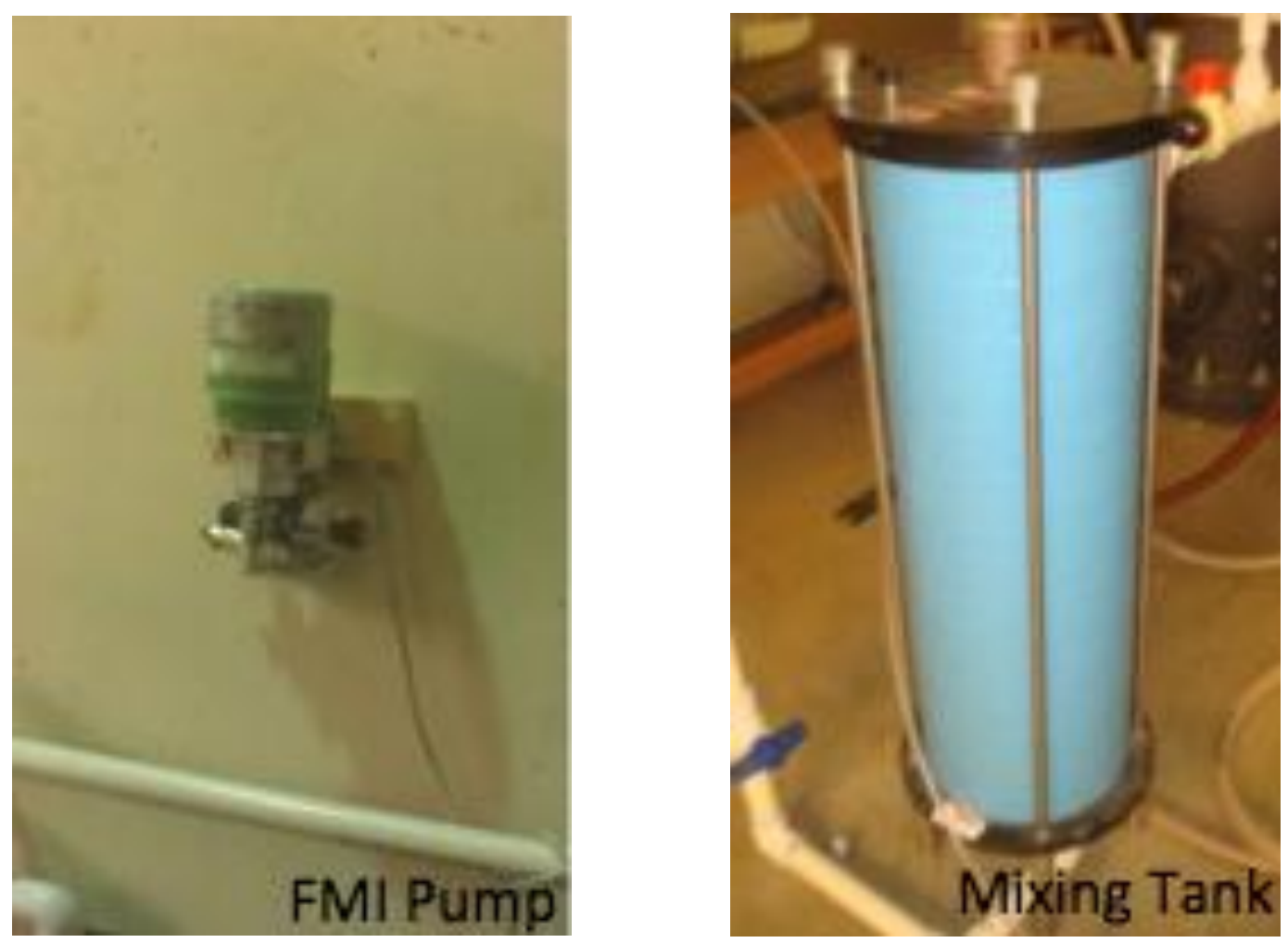

The control panel navigates the water to the right system, and through adjusting valves, back washing and direct filtration can be achieved. The flow of water and set up of valves for each process are shown in the pictures below: 

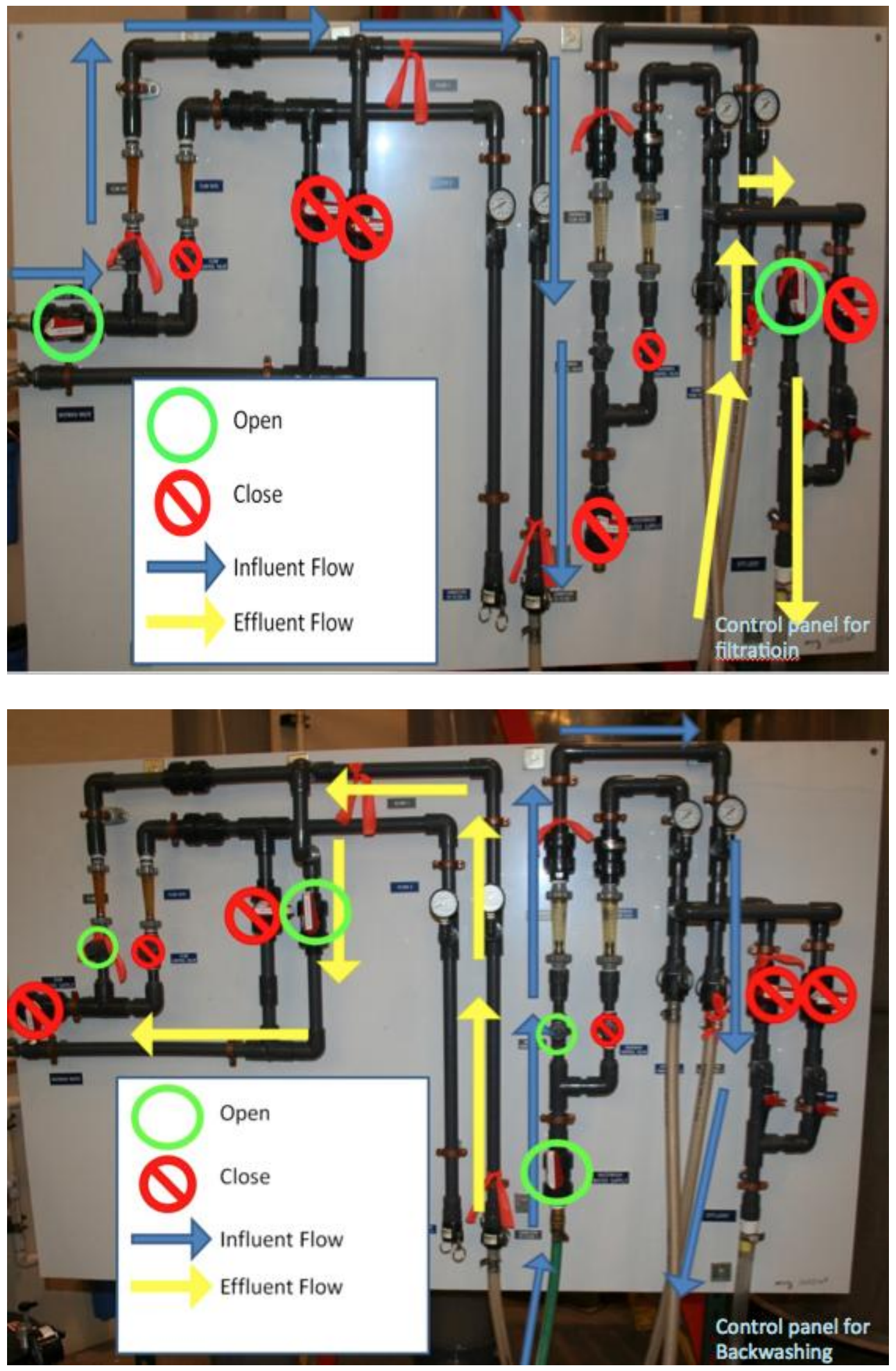
Then the water flows through the column, for flocculation and filtration.

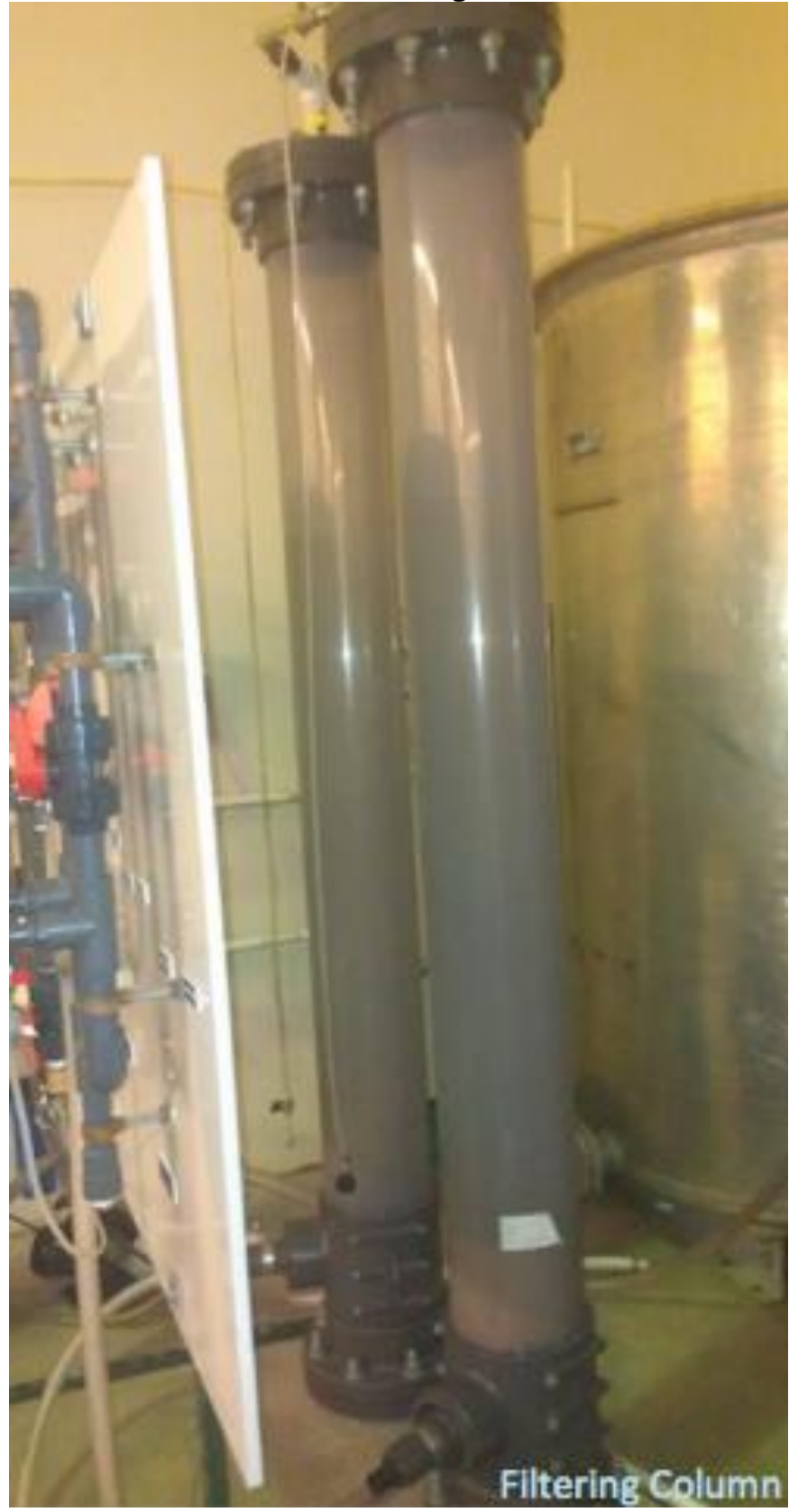

Finally the turbidity of the effluent will get measured at the inline turbidmeter, after which the water will get discharged to the drainage. 


\section{Procedure:}

\section{Week 1:}

1. Check the direct filtration apparatus; get familiar with all the valves and how to operate the two processes.

2. Determine basic parameters for the sand. Samples may be obtained from the bucket. Do a sieve analysis to determine ES and UC. Measure the density of the sand. You will need this data for calculations in following section.

3. Measure the turbidity of tap water and the final lake water. Triplicates shall be conducted for both. Record both temperature and $\mathrm{pH}$ of the turbidity water.

4. Switch the valves to proper position for back washing. Perform backwashing using tap water with the air scour on for $10 \mathrm{~min}$, then turn off the air scour until the turbidity of the effluent is lower than 0.6 NTU. Record the total time used for back washing. Calculate the back washing flow rate from question 1.

5. After backwashing, run clean water through the system until the turbidity of effluent is less than 0.5 NTU.

6. Fill the tank with 300 gallons lake water; spike the lake water with bentonite solution at the jar testing station to create a turbidity of 5 15 NTU. It is recommended that the students measure the turbidity of a diluted bentonite solution to calculate the mixing ratio for spiking.

7. Switch the valves on the pump to circulating mode, turn on the pump, and let the turbidity water mix for 15 minutes. Take three samples from the bottom of the tank and three samples from the top of the tank, measure the turbidity. Make sure the difference of the turbidities is within $5 \%$.

8. Switch the valves again to feed turbidity water to the system. Turn on the pump, use the flow regulator in the system to create a flow rate of $3 \sim 5 \mathrm{~L} / \mathrm{min}$. Turn off the PMI pump which feeds coagulant. Prepare a table as below, record all the values. Run until the turbidity of effluent exceeds 1 NTU. 


\begin{tabular}{|c|c|c|c|c|c|c|}
\hline $\begin{array}{c}\text { Time, } \\
\text { min }\end{array}$ & $\begin{array}{c}\text { Influent } \\
\text { Turbidity, } \\
\text { NTU }\end{array}$ & $\begin{array}{c}\text { Effluent } \\
\text { Turbidity, } \\
\text { NTU }\end{array}$ & $\begin{array}{c}\text { Pressure } \\
\text { reading } \\
\text { before filter }\end{array}$ & $\begin{array}{c}\text { Pressure } \\
\text { reading after } \\
\text { filter }\end{array}$ & $\begin{array}{c}\text { FMI } \\
\text { Flow } \\
\text { rate }\end{array}$ & $\begin{array}{c}\text { System } \\
\text { Flow rate }\end{array}$ \\
\hline & & & & & & \\
\hline & & & & & & \\
\hline
\end{tabular}

Week 2:

1. Switch the valves on the control panel to backwashing mode. Perform back washing as you did during week 1.

2. Prepare $10 \mathrm{~L}$ of $0.2 \mathrm{~g} / \mathrm{L}$ alum solution, measure $\mathrm{pH}$, Alkalinity. Adjust $\mathrm{pH}$ to around 7.

3. Mix the tank using the circulating pump for 5 minutes. Take samples from the sample port and measure the turbidity to make sure the water has been totally mixed.

4. Adjust the FMI pump to create a flow rate that you have calculated in question 2.

5. Set up the system for filtration. Use the same inflow rate as you used during week 1. Record the values shown in the table above every 2 minutes.

6. Repeat step 1 of week 2.

7. Clean up everything in the lab zone, flush the system under backwashing mode. Turn the valves to off position so that the water doesn't leak.

\section{Data Analysis and questions:}

1. Calculate the back washing flow rate to reach $30 \%$ filter expansion. You may need to look up the parameters for sand in table 11-5 in the textbook. (Refer to Example 11-4 in the textbook. Page 753)

2. Calculate the PMI pump rate that you needed in order to create an alum concentration of $9 \mathrm{mg} / \mathrm{L}$ in the system. Use a mass balance to solve the problem. 
3. Plot the breakthrough curve for the filtration, with and without coagulation. Compare the curves and the filter capacity in each case. Try to explain the difference.

4. Calculate the clean bed head loss and compare it with the reading from the pressure gage. Explain sources of difference. (Refer to Example 11-2 in the textbook. Page 747)

5. Other than the dosage of coagulant and the filtering material, what else can you think of that can affect the performance of a direct filtration apparatus and explain how they affect it (you may search for some literature for help).

6. Use the Tajagopalan and Tien Modle described in the textbook (Page 764) to predict treatment performance if you are using anthracite instead of sand as filter media. Use typical values from table 11-4. Assume a size of $0.1 \mu \mathrm{m}$ for the particles in the water. Assume turbidity and TSS follows a linear relationship. Use the parameters in below: (Refer to Example 11-6 in the textbook. Page 767)

Attachment efficiency: $\alpha=0.8$

Hamaker constant: $\mathrm{Ha}=10^{-20} \mathrm{~J}$

Boltzmann constant: $K_{B}=1.381 \times 10^{-23} \mathrm{~J} / \mathrm{K}$

7. If the water load in your treatment plant has received a suddenly increase and your supervisor decided that you need to add another layer of GAC to the system, what particle size would you chose if back wash hydraulics is the only consideration?

8. Compare the common treatment methods for turbidity for the advantages and disadvantages.

9. List things that you think need to be done that can improve this lab 